\title{
Single-phase mixed convection of developing and fully developed flow in smooth horizontal circular tubes in the laminar and transitional flow regimes
}

\author{
J. P. Meyer* and M. Everts
}

*Author for correspondence

Department of Mechanical and Aeronautical Engineering, University of Pretoria, Pretoria, 0002,

South Africa, E-mail: josua.meyer@up.ac.za

\section{Highlights}

- Three laminar regions: Forced- and Mixed Convection Developing and Fully Developed.

- Thermal entrance length correlations for forced and mixed convection laminar flow.

- Local and average laminar Nusselt number correlations for mixed convection flow.

- Influence of free convection on the laminar-turbulent transition.

\begin{abstract}
Correlations to calculate the local and average heat transfer coefficients for single-phase laminar flow through horizontal circular tubes with a constant heat flux boundary condition are usually restricted to fully developed flow, high Prandtl numbers or constant fluid properties. What further complicates the heat transfer characteristics of developing flow, is the local transition from laminar to turbulent flow along the tube length, above the critical Reynolds number. The purpose of this study was to investigate the effects of free convection on the development of the local heat transfer characteristics in smooth horizontal circular tubes heated with a constant heat flux. An experimental set-up was designed, built, and results were validated against literature. Two smooth circular test sections with inner diameters of $4 \mathrm{~mm}$ and $11.5 \mathrm{~mm}$ were used, and the maximum length-to-diameter ratios were 1373 and 872, respectively. Heat transfer measurements were taken at Reynolds numbers between 500 and 10000 at different heat fluxes. A total of 1046 mass flow rate measurements and 89459 temperature measurements were taken. Water was used as the test fluid and the Prandtl number ranged between 3 and 7. Three different regions were identified for developing laminar flow and were qualitatively and quantitatively defined. Correlations were developed to determine the thermal entrance lengths, as well as local and average Nusselt numbers for developing and fully developed laminar flow in mixed convection conditions with a constant heat flux boundary condition. In the transitional flow regime, the laminar-turbulent transition along the tube length was divided into four regions, and it was
\end{abstract}


found that the flow transitioned faster with increasing free convection effects and Reynolds number.

\section{Graphical abstract}

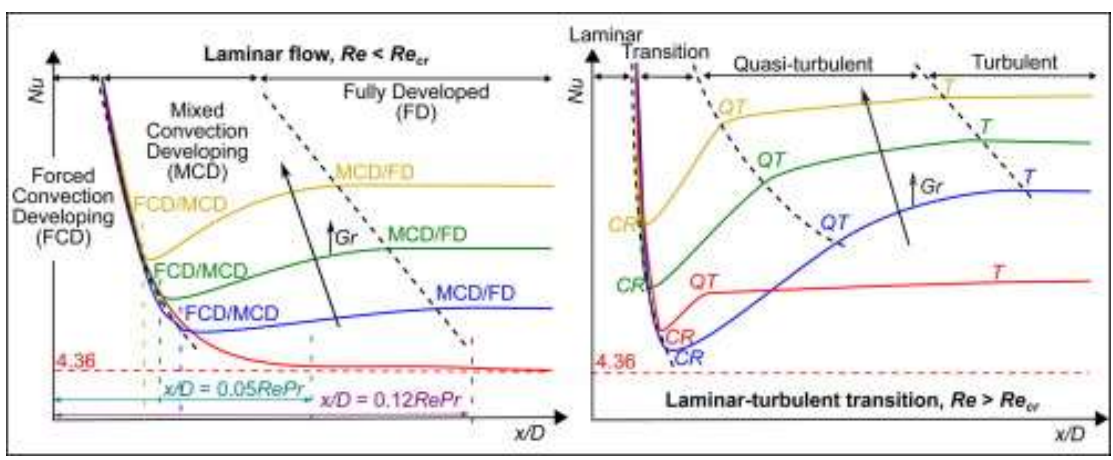

Keywords: Developing flow; laminar; transitional; heat transfer; constant heat flux; forced convection; mixed convection

\section{Nomenclature}

A Area

C Coefficient used in correlations

$C_{1-4} \quad$ Constant used in correlations

$C_{p} \quad$ Constant-pressure specific heat

$D \quad$ Inner diameter

$D_{o} \quad$ Outer diameter

$E B \quad$ Energy balance

$f \quad$ Friction factor

$g \quad$ Gravitational acceleration

Gr Grashof number

$G r^{*} \quad$ Modified Grashof number

$G z \quad$ Graetz number

$h \quad$ Heat transfer coefficient

I Current

$j \quad$ Colburn $j$-factor

$k \quad$ Thermal conductivity

$L \quad$ Length

$L t \quad$ Thermal entrance length

$M \quad$ Measurement or calculated value

$\dot{m} \quad$ Mass flow rate

$n \quad$ Total

$\mathrm{Nu} \quad$ Nusselt number

$P \quad$ Pressure

$\mathrm{Pr} \quad$ Prandtl number

$\dot{Q}_{e} \quad$ Electrical input rate

$\dot{Q}_{w} \quad$ Water heat transfer rate

$\dot{q} \quad$ Heat flux
$R_{\text {tube }}$ Thermal resistance

$R a \quad$ Rayleigh number

$R a^{*} \quad$ Modified Rayleigh number

Re Reynolds number

$R e_{c r} \quad$ Critical Reynolds number

$T$ Temperature

$V \quad$ Velocity/ voltage

$x \quad$ Distance from inlet

Greek letters

$\beta \quad$ Thermal expansion coefficient

$\varepsilon \quad$ Surface roughness

$\mu \quad$ Dynamic viscosity

$v \quad$ Kinematic viscosity

$\rho \quad$ Density

Superscripts

- $\quad$ Average

Subscripts

$b \quad$ Bulk

c Cross-section

cor Correlation

$C R$ Transition

$\exp$ Experimental

$F C \quad$ Forced convection 
$i \quad$ Inlet

$m \quad$ Mean

$o \quad$ Outer/outlet

QT Quasi-turbulent

$s \quad$ Surface

$T \quad$ Turbulent

Abbreviations (also used as italic subscripts)

FCD Forced Convection

$\begin{array}{ll}\text { FCD/MCD } & \begin{array}{l}\text { Developing region } \\ \text { Boundary between FCD } \\ \text { and MCD regions }\end{array} \\ \text { FCD/FD } & \begin{array}{l}\text { Boundary between FCD } \\ \text { and FD regions }\end{array} \\ \text { FD } & \begin{array}{l}\text { Fully Developed region } \\ \text { Mixed Convection }\end{array} \\ \text { MCD } & \begin{array}{l}\text { Developing region } \\ \text { Boundary between MCD } \\ \text { and FD regions }\end{array}\end{array}$

\section{Introduction}

The state-of-the-art of mixed convection in tubes has been reviewed (among others) in book chapters by Aung [1] and Raithby and Hollands [2], as well as in review articles by Jackson et al. [3], Orfi et al. [4], and Maré et al. [5]. These literature sources show that laminar heat transfer in horizontal circular tubes with a constant heat flux boundary condition has been extensively investigated in the past, especially between the 1950s and 1990s. As the density of almost all fluids are dependent on temperature, the addition of heat to the tube wall leads to mixed convection, due to the temperature gradients inside the thermal boundary layer that lead to density differences and buoyancy effects in the presence of gravity [6]. A lot of attention has therefore been paid to the effect of free convection on laminar heat transfer coefficients, especially when the flow is fully developed. Free convection effects not only increase the heat transfer and pressure drop, but also reduce the thermal entrance lengths and induce an early transition to turbulent flow [7].

For fluid flow in a tube with heat transfer, the thermal entrance length measured from a tube inlet is another very important aspect for design engineers. This is because it determines whether the heat transfer coefficients are dependent (developing flow) or independent (fully developed flow) on axial tube position. When high Prandtl number fluids such as oil are used, the thermal entrance length can become very long, especially at high laminar Reynolds numbers (close to the transitional flow regime). For forced convection laminar flow, the thermal entrance length is a function of Reynolds number, Prandtl number and tube diameter. According to authoritative heat transfer textbooks [8-12], the theoretical thermal entrance length can be determined as follows:

$$
\begin{gathered}
L t_{F C}=C \operatorname{RePr} D \\
\text { where } C=0.05
\end{gathered}
$$


However, very little experimental data with low uncertainties are available in literature that convincingly quantify the value of $C$ as being accurate. As will be shown later in this paper, it might be because it is very challenging to conduct forced convection experiments in tubes, and to prove that the flow is completely fully developed and the Nusselt number is 4.36 .

Siegel et al. [13] defined the thermal entrance length for laminar flow to be the heated length required for the Nusselt number to approach within 5\% of the theoretical fully developed value of 4.36 , for a constant heat flux boundary condition. A series expansion whose form is similar to the Graetz problem [14] (for a uniform wall temperature) was used and the coefficient was determined to be 0.0425 . However, according to Lienhard and Lienhard [15] the coefficients can vary between 0.028 and 0.053 , depending on the Prandtl number and wall boundary condition, when the hydrodynamic and thermal boundary layers develop simultaneously. Similar observations were made by Durst et al. [16] in a review paper on hydrodynamic entrance lengths. It was found that the coefficient varied between 0.03 and 0.062 for experimental investigations, while numerical and analytical investigations yielded coefficients between 0.025 and 0.08 .

To account for mixed convection, Hallman [17] defined the thermal entrance length as the point where the experimental curve of the local Nusselt numbers as a function of axial position crosses, meets or becomes parallel to the constant properties solution given by Siegel et al. [13]. However, this definition might lead to inaccurate results since McComas and Eckert [18] who conducted experiments using air, found that at high Grashof numbers and low Reynolds numbers, the local Nusselt numbers did not continue to decrease until flow became fully developed. Due to free convection effects, the local Nusselt numbers first decrease near the inlet of the test section, and then increase along the test section until a constant value is reached.

Similar results were obtained by Shannon and Depew [19] who conducted experiments using water. Although it seemed from their results as if free convection effects increased the thermal entrance length, Bergles and Simonds [20] reported from the work of Petukhov and Polyakov [21] that the entrance length decreased when free convection effects were significant. Hong et al. [22] investigated laminar flow analytically and experimentally and found that at a modified Rayleigh number of $10^{6}$, the fully developed Nusselt number, $\mathrm{Nu}$, was approximately $300 \%$ greater than the constant property prediction $(N u=4.36)$, while the thermal entrance length was only one tenth of the constant-property prediction $(1 / G z=0.05)$. Furthermore, although free convection effects were significant in their studies, the local 
Nusselt numbers decreased and became constant, and did not increase as was found in other mixed convection studies conducted at high Grashof numbers.

Cheng and $\mathrm{Ou}$ [23] numerically investigated free convection effects in large Prandtl number fluids. Similar to the results obtained by Hong et al. [22], it was found that when the Rayleigh number was greater than $3.75 \times 10^{5}$, the local Nusselt numbers decreased along the tube length and became constant. However, three regions with different heat transfer mechanisms were observed from the local Nusselt numbers when the Rayleigh number was less than $3.75 \times 10^{5}$. Region 1 was named the Leveque solution region and the local Nusselt numbers decreased with axial position, due to the entrance effect. In this region, the convective terms due to free convection were negligible compared to the axial convective term. A minimum Nusselt number was reached once the free convection and entrance effects were balanced. Free convection effects were significant in the intermediate region (region 2), and caused the local Nusselt numbers to increase along the tube length. The free convection effects dominated the entrance effects up to a point where the local Nusselt numbers reached a maximum. The local Nusselt numbers then decreased until an asymptotic value was reached in region 3. Although these three regions were observed by Cheng and $\mathrm{Ou}$ [23], the boundaries between the three regions were not defined qualitatively and quantitively. This is done in this paper in Section 9.3.

Barozzi et al. [24] conducted experiments using water and also found that the local Nusselt numbers reached a minimum before they began to increase and became constant. However, due to the small amount of experimental data, no correlations were attempted by the authors. Shah [25] developed empirical correlations to calculate the average Nusselt numbers of developing flow with a constant heat flux boundary condition. However, as these correlations are valid for constant fluid properties, they do not accurately account for free convection effects.

Although extensive research has been performed on the thermal entrance length in the laminar flow regime, some gaps in literature remain once free convection conditions become significant. There is not only uncertainty regarding an appropriate correlation to calculate the thermal entrance length, but also with the definition of the point of fully developed flow in mixed convection heat transfer. Furthermore, while laminar heat transfer correlations are readily available in heat transfer textbooks, these equations and graphs are usually based on analytical solutions to the governing equations for laminar flow. It is therefore restricted to constant fluid properties, while this assumption is not valid in actual practice [20]. The differing behaviour of the local heat transfer characteristics of differing Prandtl number fluids 
when mixed convection effects exists, made it even more challenging to obtain a single correlation [23].

What further complicates the heat transfer characteristics of developing flow, is the local transition from laminar to turbulent flow along the tube length above the critical Reynolds number. Nishi et al. [26] gives a comprehensive review of the work that has been done on the laminar-turbulent transition along a tube length. Previous studies focussed mainly on the effect of inlet disturbances and Reynolds number on the two different flow structures (puffs and slugs) that occur during transition.

The transitional flow regime itself has also been extensively investigated by Ghajar and co-workers [27-36] as well as Meyer and co-workers [37-44], however, the focus of these studies were on the effects on inlet geometries, enhanced tubes, nanofluids, micro-channels, annuli and twisted tape inserts. While Ghajar and co-workers considered mainly fully developed flow, Meyer and co-workers used the average measurement across a tube length. The previous work did not focus on the local heat transfer characteristics itself, and specifically the effect of free convection on the development of the flow from laminar to turbulent along the tube length (as is investigated in this paper).

The aim of this study is therefore to investigate the effects of free convection on the development of the local heat transfer characteristics along the tube length. The specific objectives are: (1) to evaluate the thermal entrance length correlations for forced convection conditions, (2) to develop correlations to determine the thermal entrance length for mixed convection conditions, (3) to develop correlations to predict the local and average Nusselt numbers and friction factors of both developing and fully developed flow and which are valid for both high and low Prandtl number fluids, as well as (4) to investigate the effect of free convection on the laminar-turbulent transition along the tube length in the transitional flow regime.

This paper forms part of a bigger study and is complimentary to the papers published by Everts and Meyer [45-47]. This paper investigated mixed convection laminar flow, as well as the effect of free convection on the laminar-turbulent transition along the tube length. Everts and Meyer [45] investigated the heat transfer characteristics of developing and fully developed flow in the transitional flow regime, while the relationship between heat transfer and pressure drop in all flow regimes was investigated and quantified in Everts and Meyer [46]. The results of these papers were used to develop the flow regime maps, for not only fully developed flow but also developing flow, presented in Everts and Meyer [47]. 


\section{Experimental set-up}

The layout of the experimental set-up is shown in Fig. 1. The experimental set-up consisted of a closed-loop system, which circulated water from a storage tank, through the test section and back to the storage tank, using two electronically controlled magnetic gear pumps with a maximum flow rate of $270 \mathrm{l} / \mathrm{h}$. As the laboratory was temperature-controlled (24/7) to a constant temperature of $21.8^{\circ} \mathrm{C}$, it was possible to conduct experiments at the same ambient conditions throughout a total period of three years. The test fluid was chosen as water and the capacity of the storage tank was $260 \ell$ which was maintained at a preselected temperature $\left(20^{\circ} \mathrm{C}\right)$, as it was externally connected to a thermostat-controlled bath that cooled the heated water. The water in the storage tank was continuously pumped through a filtration cycle to remove solid particles that might have entered the system, as well as to enhance mixing and prevent thermal stratification inside the storage tank.

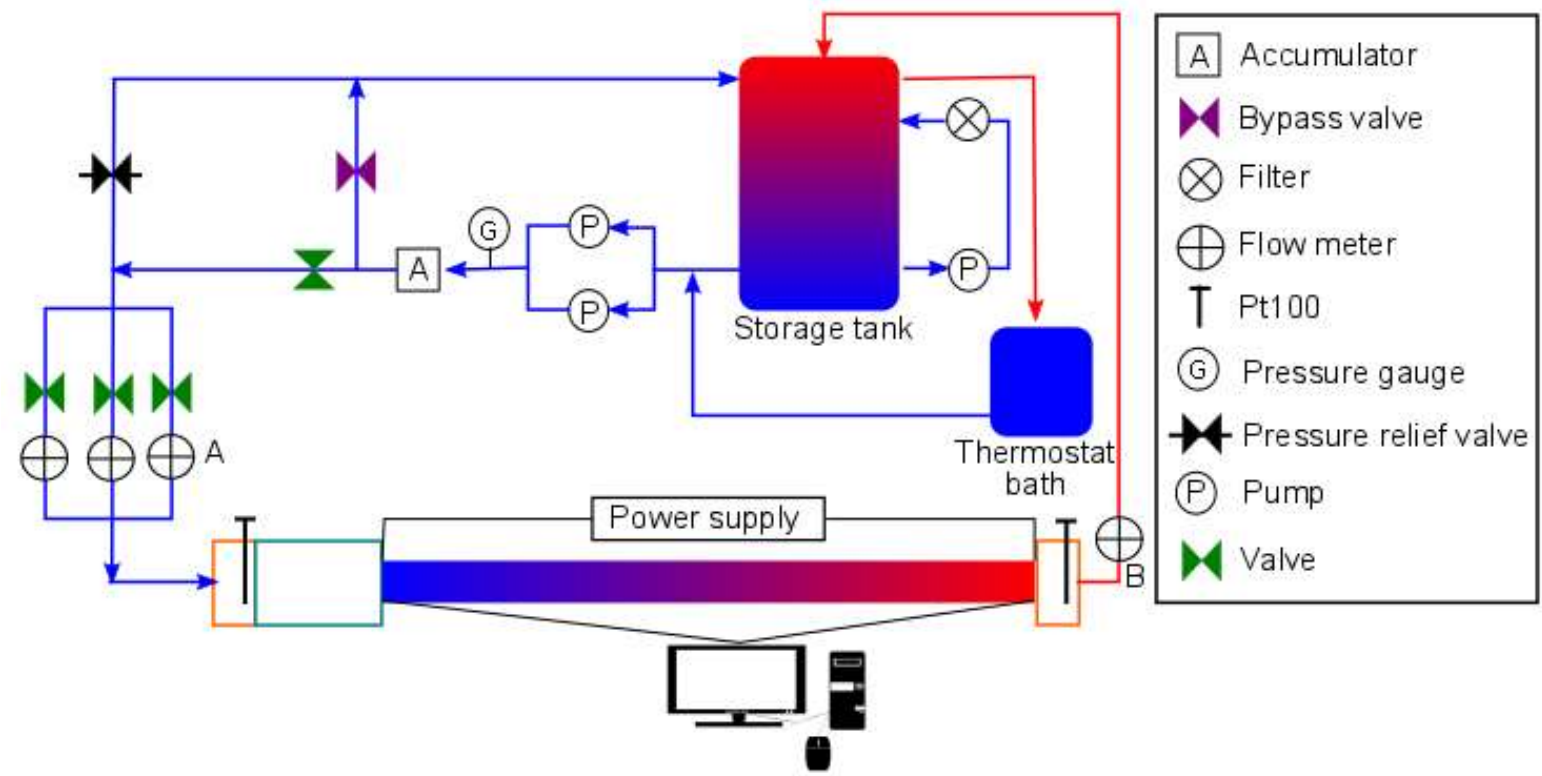

Fig. 1: Schematic representation of the experimental set-up used to conduct heat transfer and pressure drop measurements. Water was circulated from the storage tank through the test section and back using two pumps. Flow meter bank A was used to conduct experiments with the $11.5 \mathrm{~mm}$ test section and flow meter $B$ was used for the $4 \mathrm{~mm}$ test section.

A $0.74 \ell$ bladder accumulator was installed upstream of the flow meters and the test section to dampen possible pulsations from the pump that might have an effect on transition. This ensured a constant pressure and mass flow rate at the inlet of the test section. A bypass valve was inserted after the accumulator to allow a fraction of the water to flow back to the tank. During experiments, the supply valve was partially closed and the bypass valve partially opened, so that the pump was operated at close to its maximum speed, to ensure a preselected mass flow rate of water to the test section. The increased pump speed, as well as 
the artificial increase in pressure at the pump inlet (monitored using the pressure gauge), led to decreased mass flow rate pulsations. The valve positions were adjusted throughout the experiments to minimise the flow pulsations for all the measurements. A pressure relief valve was installed to allow the water to flow directly to the storage tank if the pressure exceeded the preselected threshold.

As the mass flow rates varied over a wide range, Coriolis mass flow meters with different flow rate capacities were installed in parallel. The mass flow meter that would produce the most accurate mass flow rate measurements was selected during the experiments. All measurements that were conducted were within the prescribed ranges of the mass flow meters. The mass flow rates were controlled by frequency drives that were connected to the pump. The required mass flow rate was therefore obtained by increasing or decreasing the pump speed. Downstream of the mass flow meters, the fluid flowed through a flow-calming section to the test section and mixer, and then back into the storage tank.

\subsection{Flow-calming section}

A flow-calming section, similar to the one used by Ghajar and co-workers [27-35, 48, 49] was installed upstream of the test section to straighten the flow. The flow-calming section was made form clear acrylic plastic to ensure that entrained air bubbles could be detected. The acrylic tube had an inner diameter and length of $172 \mathrm{~mm}$ and $700 \mathrm{~mm}$, respectively. To prevent any temperature gradients inside the flow-calming section, the fluid first flowed through a $100 \mathrm{~mm}$ cavity filled with a soft nylon mesh, before it reached a Pt100 probe, where the average inlet temperature was measured. Three perforated acrylic plates with an open-area ratio (OAR) of 0.299 (73 holes with a diameter of $11 \mathrm{~mm}$ ) were inserted after the Pt100 and were followed by tightly packed soda straws (inside diameter $5.1 \mathrm{~mm}$, length $102 \mathrm{~mm}$, OAR of 0.855), between two galvanised steel meshes (wire diameter 0.37, OAR of 0.588). The fluid passed through another galvanised steel mesh (wire diameter 0.37, OAR of 0.588 ) before leaving the flow-calming section. The inlet section was bolted to the flowcalming section and consisted of a clear acrylic tube with an inside diameter and length of $172 \mathrm{~mm}$ and $195 \mathrm{~mm}$, respectively. An acetal disc was bolted to the inlet section to obtain a square-edged inlet.

A bleeding valve was installed prior to the inlet section to bleed air that entered the flowcalming section. The Pt100 connection inside the flow-calming section was used as another bleeding valve. The flow-calming section was properly insulated against heat loss using 
$40 \mathrm{~mm}$ thick insulation with a thermal conductivity of $0.034 \mathrm{~W} / \mathrm{m} . \mathrm{K}$. Peeping holes and lids were incorporated into the insulation to be able to detect air bubbles.

\subsection{Test sections}

An acetal disc with a diameter of $260 \mathrm{~mm}$ and thickness of $40 \mathrm{~mm}$ was used to connect the flow-calming section to the test sections (Fig. 2). The thermal conductivity of acetal is $0.31 \mathrm{~W} / \mathrm{m} . \mathrm{K}$, which is very low in comparison to the thermal conductivity of the test sections, and thus the acetal disc was also used to prevent axial heat conduction from the test section to the flow-calming section. To ensure a proper square-edged inlet, care was taken to ensure that the start of the test section was flush with the start of the acetal cylinder. Two test sections, with inner diameters of $11.5 \mathrm{~mm}$ and $4 \mathrm{~mm}$, respectively, were used to investigate the influence of tube diameter and heating method. The test sections are shown schematically in Fig. 2.
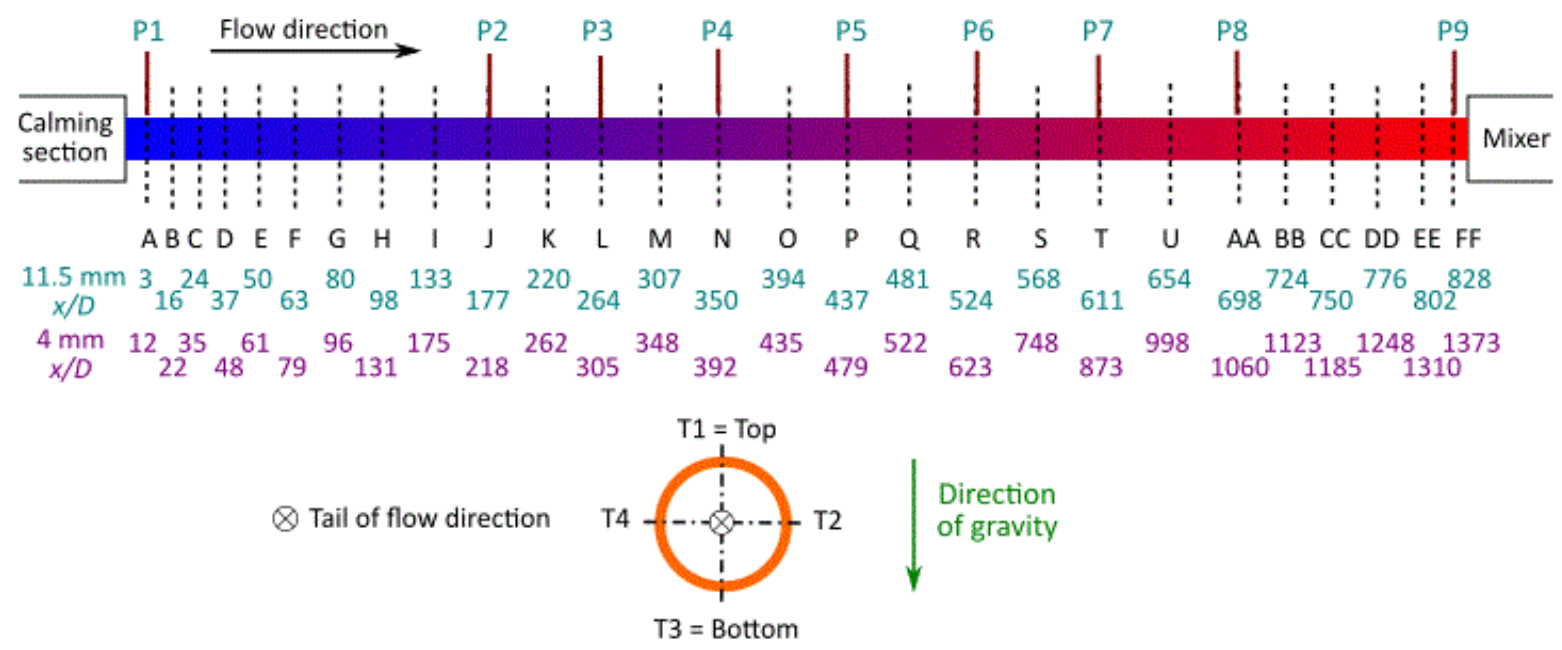

Fig. 2: Schematic representation of the test sections indicating the 27 thermocouples stations, $A$ to $F F$, on the $11.5 \mathrm{~mm}$ and $4 \mathrm{~mm}$ test sections, as well as the nine pressure taps, P1 to P9, on the $11.5 \mathrm{~mm}$ test section. The $x / D$ values of the thermocouples stations of both test sections, are also given. A cross-sectional view of the test section is included to illustrate the four thermocouple positions spaced around the outside periphery of the tube.

The $11.5 \mathrm{~mm}$ test section was manufactured from a hard-drawn copper tube with an average measured (with a split-ball unit and a vernier calliper) inside diameter of $11.52 \mathrm{~mm}$, outside diameter of $12.7 \mathrm{~mm}$, and a length of $9.81 \mathrm{~m}$ (with a measuring tape). However, to prevent possible upstream flow effects from influencing the measurements at the last measuring station (station FF), $300 \mathrm{~mm}$ was allowed between the last measuring station (at $x=9.5 \mathrm{~m}$ ) and the mixer (at $x=9.8 \mathrm{~m}$ ).

The $4 \mathrm{~mm}$ test section was manufactured from a seamless $316 \mathrm{~L}$ stainless steel tube with an inner and outer diameter of $4 \mathrm{~mm}$ and $6 \mathrm{~mm}$, respectively, and a length of $6 \mathrm{~m}$. However, 
measurements were only taken across the first $5.5 \mathrm{~m}$. The remaining $500 \mathrm{~mm}$ between the last measuring station and mixer was, as with the $11.5 \mathrm{~mm}$ test section, to prevent possible upstream effects from influencing the measurements at the last thermocouple station.

The average surface roughness $(\varepsilon)$ of the $11.5 \mathrm{~mm}$ copper test section and $4 \mathrm{~mm}$ stainless steel test section was measured using a surface roughness tester, to be approximately $0.218 \mu \mathrm{m}$ and $0.138 \mu \mathrm{m}$, respectively. The relative surface roughness $(\varepsilon / D)$ was therefore $1.89 \times 10^{-5}$ and $3.45 \times 10^{-5}$, and for all practical purposes, both tubes can be considered as being smooth. The total length of the $11.5 \mathrm{~mm}$ and $4 \mathrm{~mm}$ test sections provided maximum lengthto-inside diameter ratios $(x / D)$ of 828 and 1373 , respectively, while previous investigations by Ghajar and co-workers [27-29, 31, 32, 34, 35] and Meyer and Olivier [37] had maximum values of 400 and 350, respectively. The test sections in this study were thus 2-4 times longer than was used in previous studies.

The details of the pressure taps and measurements are given in Everts and Meyer [46]. Ttype thermocouples with a wire diameter of $0.25 \mathrm{~mm}$ and accuracy of $0.1^{\circ} \mathrm{C}$ were used to measure the surface temperatures at 27 selected axial locations on both test sections. The thermocouple stations were spaced closer to each other near the inlet of the test section to accurately obtain the temperature profile of developing flow, while the thermocouple stations were spaced further apart on the rest of the test section where the flow was expected to be fully developed. To compare the developing heat transfer results in the $4 \mathrm{~mm}$ and $11.5 \mathrm{~mm}$ test sections, the same non-dimensional axial positions were used on both test sections for $x / D<524$. As the diameter of the $4 \mathrm{~mm}$ test section was 2.88 times smaller than the $11.5 \mathrm{~mm}$ test section, the maximum length-to-inside diameter ratio $(x / D)$ was 1.66 times larger than that of the $11.5 \mathrm{~mm}$ test section. To obtain sufficient heat transfer results in the remaining part of the $4 \mathrm{~mm}$ test section, the thermocouples were located at $500 \mathrm{~mm}$ intervals for $524<x / D<873$, and at $250 \mathrm{~mm}$ intervals for $873<x / D<1373$. To investigate possible circumferential temperature distributions caused by free convection effects along the tube length, four thermocouples (spaced $90^{\circ}$ apart around the periphery) were used at each thermocouple station on the $11.5 \mathrm{~mm}$ test section, and on the $4 \mathrm{~mm}$ test section for $x / D<524$. The remaining thermocouple stations on the $4 \mathrm{~mm}$ test section (stations $\mathrm{R}$ to $\mathrm{FF}$ ) contained thermocouples at the top and bottom of the test section, and one thermocouple on the side only. The third thermocouple alternated between the left (T4 in Fig. 2) and right (T2 in Fig. 2) side of the test section.

The thermocouples were attached to the $11.5 \mathrm{~mm}$ copper test section by first drilling a $0.3 \mathrm{~mm}$ indentation into the tube. Solder was inserted into the indentation and heated up to 
the melting point. The thermocouple was then inserted into the indentation and the heat was removed, allowing the solder to cool down. The thermocouples were carefully checked to ensure good contact with the tube. As the wall thickness of the $4 \mathrm{~mm}$ stainless steel tube was $1 \mathrm{~mm}, 0.5 \mathrm{~mm}$ indentations were drilled into which the thermocouples were placed. A 3D printed jig was used to ensure that all the holes were drilled to the same depth. The thermocouples were glued to the stainless steel tube using a thermal adhesive with a thermal conductivity of $9 \mathrm{~W} / \mathrm{m} . \mathrm{K}$, and a curing time of 5 minutes.

The thermocouples of both test sections were calibrated in-situ to an accuracy of $0.1^{\circ} \mathrm{C}$ by pumping water from a thermostat-controlled bath through the flow-calming section, test section and mixer, and back into the thermostat-controlled bath. Reference temperatures were obtained using Pt100 probes at the inlet of the flow-calming section, at the outlet of the mixer and in the thermostat-controlled bath. The temperature of the thermostat-controlled bath was varied between $20^{\circ} \mathrm{C}$ and $60^{\circ} \mathrm{C}$.

Two different heating methods were used in this study, because of the availability of equipment. To obtain a constant heat flux boundary condition in the $11.5 \mathrm{~mm}$ copper test section, four constantan wires (with a high electrical resistance) with a diameter of $0.38 \mathrm{~mm}$ were coiled around the test section. The heating wires were connected in parallel to obtain the desired resistance, while limiting the current flowing through each wire. When coiling the heating wire, it was important to consider how close the heating wire could be to the thermocouple junction before affecting the temperature measurements. Everts [50] experimentally investigated different coiling techniques and concluded that a gap of approximately $1 \mathrm{~mm}$ between the heating wire and the thermocouple junction was sufficient.

A constant heat flux boundary condition was obtained in the $4 \mathrm{~mm}$ stainless steel test section, by passing current through the tube wall. The resistance of the stainless steel tube was measured to be $0.282 \Omega$ in the temperature-controlled laboratory, using a multimeter. The test section was electrically insulated with Kapton film before it was thermally insulated. Both test sections were thermally insulated with $120 \mathrm{~mm}$ thick Armaflex insulation with a thermal conductivity of $0.034 \mathrm{~W} / \mathrm{m} . \mathrm{K}$. The maximum heat loss was estimated with onedimensional conduction heat transfer calculations to be less than $3 \%$ in both test sections.

\subsection{Mixer}

During laminar flow measurements, significant cross-sectional temperature gradients in the radial and tangential directions developed throughout the test section. Therefore, to obtain a uniform tube outlet temperature, a mixer was inserted after the test section to mix the 
water exiting the test section. The purpose of the mixer was twofold: to house the splitter plates, as well as to house a Pt100 probe that was used to measure the average outlet temperature.

The mixer design was based on work done by Bakker et al. [51], who investigated laminar flow in static mixers with helical splitter plates. The mixer consisted of four copper splitter plates, with a length-to-diameter ratio of 1.5. The elements were positioned and soldered such that the leading edge of an element was perpendicular to the trailing edge of the next element. Every splitter plate repeatedly split the thermal boundary layers to ensure a uniform temperature gradient in the radial direction. The splitter plates were placed inside the acetal mixer that directed the fluid to flow over and along the Pt100, after it has been mixed. This ensured that the entire Pt100 was exposed to the mixed fluid and also eliminated any stagnant recirculation zones. The mixer was insulated with $75 \mathrm{~mm}$ thick insulation to prevent any heat loss, and air was bled from the mixer using the Pt100 connection to the mixer housing.

\subsection{Instrumentation}

\subsubsection{Power supply}

Two direct current (DC) power supplies were used to heat the $11.5 \mathrm{~mm}$ test section. Both power supplies had a maximum power output of $3 \mathrm{~kW}$, maximum voltage of $360 \mathrm{~V}$ and maximum current of $15 \mathrm{~A}$. The accuracies of both measured voltages and currents were $0.2 \%$ of the nominal value. The maximum supplied power and voltage from each power supply were $525 \mathrm{~W}$ and $355 \mathrm{~V}$, respectively, at the maximum heat flux of $3 \mathrm{~kW} / \mathrm{m}^{2}$. In an effort to reduce the effect of electromagnetic interference caused by the currents through the coiled wires, two heating wires were connected, with opposing polarities, to each power supply. According to Lenz's law, the opposing directions of current flow should produce two opposing magnetic fields, which will, in turn, largely cancel each other out [52].

As the $4 \mathrm{~mm}$ test section was heated by passing current through the stainless tube, a different power supply, with a higher current output, was used. The power supply had a maximum power output of $3 \mathrm{~kW}$, maximum voltage of $40 \mathrm{~V}$ and maximum current of $60 \mathrm{~A}$. The electrical resistivity of the tube changed during testing due to the temperature changes. Therefore, current inputs were continuously adjusted to ensure that the desired constant heat flux was obtained throughout the experiments. To account for small variations, the power that was supplied to the test section was logged and averaged. 


\subsubsection{Flow meters}

Three Coriolis flow meters (flow meter bank A in Fig. 1) with different measurement ranges were used to measure the mass flow rates in the $11.5 \mathrm{~mm}$ test section. For low mass flow rates, a flow meter with a maximum flow rate of $108 \mathrm{l} / \mathrm{h}$ was used. For mass flow rates between $60 \mathrm{l} / \mathrm{h}$ and $130 \mathrm{l} / \mathrm{h}$, a flow meter with a maximum capacity of $330 \mathrm{l} / \mathrm{h}$ was used, while a flow meter with a maximum limit of $2180 \mathrm{l} / \mathrm{h}$ was used for the higher mass flow rates. The accuracy of the flow meters was $0.05 \%$ of the full scale, thus the accuracy of the three flow meters was $0.054 \ell / \mathrm{h}, 0.165 \ell / \mathrm{h}$ and $1.09 \ell / \mathrm{h}$, respectively.

As the diameter of the $4 \mathrm{~mm}$ test section was significantly smaller than for the $11.5 \mathrm{~mm}$ test section, only a low flow rate flow meter (flow meter B in Fig. 1) was used. This flow meter was located after the mixer and had a maximum flow rate of $108 \mathrm{l} / \mathrm{h}$ and accuracy of $0.054 \ell / h$.

\subsubsection{Control and data logging}

The mass flow rate of the pump was controlled by frequency drives that were connected to a personal computer via a data acquisition system. The data acquisition system was used to record the data from the Pt100 probes (temperatures), thermocouples (temperatures), pressure transducers (pressure drops) and flow meters (mass flow rates). The data acquisition system consisted of a personal computer using National Instruments Labview software. The data acquisition system also consisted of SCXI (Signal Conditioning eXtensions for Instrumentation) hardware which included terminal blocks, analogue-to-digital converters and multiplexers. A Mathworks MATLAB script was used for the data processing.

\section{Data reduction}

As a constant heat flux boundary condition was applied to the test section, the average axial temperature of the water increased linearly. The mean fluid temperature, $T_{m}$, at a specific tube location, $x$, was obtained using a linear temperature distribution between the measured inlet, $T_{i}$, and measured outlet, $T_{o}$, temperatures of the fluid over the tube length, $L$ :

$$
T_{m}=\left(\frac{T_{o}-T_{i}}{L}\right) x+T_{i}
$$

The bulk fluid temperature, $T_{b}$, along a tube length, $L(x)$, measured from the inlet of the test section, was calculated as: 


$$
T_{b}=\left(\frac{T_{o}-T_{i}}{L}\right) \frac{L(x)}{2}+T_{i}
$$

The properties of water (density, $\rho$, dynamic viscosity, $\mu$, thermal conductivity, $k$, specific heat, $C_{p}$, Prandtl number, $\operatorname{Pr}$, and thermal expansion coefficient, $\beta$ ) were determined using the thermophysical correlations for liquid water [53] at the bulk fluid temperature for the average properties, and at the mean fluid temperature for the local properties at a specific point $x$, measured from the inlet of the test section.

The Reynolds number, $R e$, was calculated as:

$$
R e=\frac{\dot{m} D}{\mu A_{c}}
$$

where $\dot{m}$ was the measured mass flow rate, $D$ was the measured inner-tube diameter, $\mu$ was the dynamic viscosity, and $A_{\mathrm{c}}$ the cross-sectional area of the test section $\left(A_{c}=\pi / 4 D^{2}\right)$.

The electrical input rate $\left(\dot{Q}_{e}=V I\right)$ remained constant, resulting in a constant heat flux. The heat transfer rate to the water, $\dot{Q}_{w}$, was determined from the measured mass flow rate, measured inlet and outlet temperatures of the water and the specific heat which was calculated at the bulk fluid temperature:

$$
\dot{Q}_{w}=\dot{m} C_{p}\left(T_{o}-T_{i}\right)
$$

The heat transfer rate to the water, $\dot{Q}_{w}$, was continuously monitored by comparing it to the electrical input rate, $\dot{Q}_{e}$, which should ideally be equal since the test section was well insulated. The energy balance, $E B$, which ideally should be as close as possible to zero, was determined as:

$$
E B=\left|\frac{\dot{Q}_{e}-\dot{Q}_{w}}{\dot{Q}_{e}}\right| * 100=\left|\frac{V I-\dot{m} C_{p}\left(T_{o}-T_{i}\right)}{V I}\right| * 100
$$

The average energy balance of all the experiments that were conducted was less than $3 \%$, which is in good agreement with the calculations estimating the heat losses through the insulation material.

The heat flux, $\dot{q}$, on the inside of the tube wall was determined from the heat transfer rate to the water, $\dot{Q}_{w}$, and the inner surface area, $A_{s}$, of the test section along the heated length: 


$$
\dot{q}=\frac{\dot{Q}_{w}}{A_{s}}=\frac{\dot{m} C_{p}\left(T_{o}-T_{i}\right)}{\pi D L}
$$

The heat transfer rate to the water was used to determine the heat flux, since it was regarded as more accurate than the electrical input rate. As the energy balance was not zero, and some losses did occur to the ambient air, the electrical input rate was always slightly higher than the heat transfer rate to the water.

The average of the four (or three) temperature measurements at a station was used as the average outer surface temperature, $T_{s, o}$, at a specific thermocouple station:

$$
T_{s, o}=\frac{T_{1}+T_{2}+\cdots+T_{n}}{n}
$$

The thermal resistance, $R_{\text {tube }}$, across the tube wall was calculated using the following equation:

$$
R_{\text {tube }}=\frac{\ln \left(\frac{D_{o}}{D}\right)}{2 \pi k L}
$$

where $D_{o}$ and $D$ were the measured outside and inside diameters of the tube.

The thermal conductivity of copper is $401 \mathrm{~W} / \mathrm{m} . \mathrm{K}$, while the thermal conductivity of $316 \mathrm{~L}$ stainless steel is only $16.3 \mathrm{~W} / \mathrm{m} . \mathrm{K}$. The temperature differences across the tube wall, $\Delta T$, were calculated using Eq. (10), since the thermal resistance and heat input were known.

$$
\Delta T=\dot{Q}_{w} R_{\text {tube }}
$$

The thermal resistance in the $11.5 \mathrm{~mm}$ test section was calculated to be $4.05 \times 10^{-6}{ }^{\circ} \mathrm{C} / \mathrm{W}$ for the tube, as the wall thickness was $0.6 \mathrm{~mm}$. Therefore, the temperature difference across the tube wall was approximately $0.004^{\circ} \mathrm{C}$ when the maximum heat input $\left(3 \mathrm{~kW} / \mathrm{m}^{2}\right)$ was applied to the test section. The negligible temperature difference led to the assumption that the temperature on the inside surface of the test section was equal to the temperature measurement on the outside surface of the test section, since the temperatures in general could only be measured to an accuracy of $0.1^{\circ} \mathrm{C}$. It was therefore assumed that the surface temperatures, determined from Eq. (8), was the average surface temperature on the inside of the tube at a measuring station in the $11.5 \mathrm{~mm}$ test section. 
The thermal resistance in the $4 \mathrm{~mm}$ stainless steel tube was calculated to be $3.63 \times 10^{-}$ ${ }^{4} \mathrm{C} / \mathrm{W}$, which is two orders of magnitude more than in the $11.5 \mathrm{~mm}$ copper tube. Although the thermocouples in the $4 \mathrm{~mm}$ test section were placed in an $0.5 \mathrm{~mm}$ deep indentation in the tube wall, the temperature difference across the remaining $0.5 \mathrm{~mm}$ was approximately $0.2^{\circ} \mathrm{C}$ when the maximum heat input $\left(8 \mathrm{~kW} / \mathrm{m}^{2}\right)$ was applied to the test section. As this was not negligible, the temperature difference calculated using Eqs. (9) and (10) was subtracted from the measured surface temperatures (Eq. (8)) to obtain the temperature on the inside of the $4 \mathrm{~mm}$ test section.

From this, the inner surface temperatures, $T_{s}$, of the test section were determined as:

$$
T_{s}=T_{s, o}-\Delta T=T_{s, o}-\dot{Q}_{w} R_{\text {tube }}
$$

As heat was applied to the $4 \mathrm{~mm}$ test section by passing current through the tube wall (and not using heating wire coiled around the outer surface of the tube), the finite difference formulations of Ghajar and Kim [54] can be used to determine the inner surface temperatures. However, the simpler method of Morcos and Bergles [55], that consists of a two-dimensional conduction equation and also accounts for both radial and peripheral heat transfer, was used. The results were compared with those obtained using Eq. (10), and it was found that at the maximum heat flux of $8 \mathrm{~kW} / \mathrm{m}^{2}$, the difference was $0.1^{\circ} \mathrm{C}$ but reduced to $0.01^{\circ} \mathrm{C}$ when the heat flux was decreased to $1 \mathrm{~kW} / \mathrm{m}^{2}$. As this was within the uncertainty of the thermocouples $\left(0.1^{\circ} \mathrm{C}\right)$, it confirmed that Eq. (10) was able to provide reliable results. Therefore, similar to Morcos \& Bergles [55], it was decided to use the simpler one-dimensional method (Eq. (10)) in this study.

The average surface temperature, $\bar{T}_{s}$, along a tube length, $L(x)$, measured from the inlet of the test section, was calculated as:

$$
\bar{T}_{s}=\frac{1}{L(x)} \int_{0}^{L(x)} T_{s}(x) d x
$$

The heat transfer coefficients, $h$, were then determined from the following equation, since the heat flux, $\dot{q}$, surface temperature, $T_{s}$, and mean fluid temperature, $T_{m}$, were known:

$$
h=\frac{\dot{q}}{\left(T_{s}-T_{m}\right)}
$$


The Nusselt numbers, $\mathrm{Nu}$, were determined from the heat transfer coefficients as follows:

$$
N u=\frac{h D}{k}
$$

The heat transfer results were also investigated in terms of the Colburn $j$-factors, to account for the variations in the Prandtl numbers:

$$
j=\frac{N u}{\operatorname{RePr}^{\frac{1}{3}}}
$$

The Graetz numbers, $G z$, were determined as:

$$
G z=\operatorname{RePr} \frac{D}{x}
$$

while the Grashof numbers, $G r$, were determined using the following equation:

$$
G r=\frac{g \beta\left(T_{s}-T_{m}\right) D^{3}}{v^{2}}
$$

where $9.81 \mathrm{~m} / \mathrm{s}^{2}$ was used for the gravitational acceleration, $g$, and the kinematic viscosity was obtained from the density and dynamic viscosity $(v=\mu / \rho)$.

The modified Grashof numbers, $G r^{*}$, which are a function of heat flux instead of temperature differences, are the product of the Grashof numbers and Nusselt numbers and were determined as follows:

$$
G r^{*}=G r N u=\frac{g \beta \rho \dot{q} D^{4}}{v^{2} k}
$$

The Rayleigh numbers, $R a$, were determined as the product of the Grashof numbers and Prandtl numbers:

$$
\begin{aligned}
R a & =G r P r \\
R a^{*} & =G r^{*} P r
\end{aligned}
$$

Eqs. (13) - (20) were for the local values at a specific axial position along the tube length. The average values along a tube length, $L(x)$, measured from the inlet of the test section, were obtained by using the bulk fluid temperature (Eq. (3)) and average surface temperature (Eq. 
(12)), instead of the mean fluid temperature (Eq. (2)) and local surface temperature (Eq. (11)).

The average friction factors, $\bar{f}$, were also calculated from the mass flow rate and pressure drop measurements, $\Delta P$, across the different tube lengths:

$$
\bar{f}=\frac{2 \Delta P D}{L(x) \rho V^{2}}=\frac{\Delta P \rho D^{5} \pi^{2}}{8 \dot{m}^{2} L(x)}
$$

In general, the percentage error of a measurement or calculated value $(M)$ was determined as, \%error $=\left|M_{\text {exp }}-M_{c o r}\right| / M_{c o r} \times 100$. The average percentage error was taken as the average of the absolute errors of the data points.

\section{Uncertainty analysis}

The method suggested by Dunn [56] was used to calculate the uncertainties of the parameters obtained in the data reduction. All uncertainties were calculated within a 95\% confidence interval. The uncertainty analysis details are given in Everts [57]. The Reynolds number uncertainties were approximately $1.5 \%$ in the laminar and turbulent flow regimes, and increased to $2 \%$ in the transitional flow regime due to the mass flow rate fluctuations that occurred in this flow regime. The laminar forced convection Nusselt number uncertainties were less than $10 \%$, while the laminar mixed convection uncertainties were less than $5 \%$, and decreased with increasing heat flux. In the transitional flow regime, the uncertainties increased to approximately $10 \%$ (depending on the heat flux), due to the temperature fluctuations. The Nusselt number uncertainties in the turbulent flow regime increased with increasing Reynolds number and the average Nusselt number uncertainty at a Reynolds number of 6000 was $13 \%$.

\section{Experimental procedure}

Steady-state conditions were reached after approximately one hour after initiating an experiment. Steady-state conditions were assumed once there was no significant increase or decrease in temperatures, pressure drops and mass flow rates, within a period of approximately two minutes. After the initial steady-state was achieved, the mass flow rate was increased in large increments in the laminar and turbulent regions, and in smaller increments in the regions where transition was noticed. The time required to reach steadystate depended on the mass flow rate inside the test section and the heat flux. In the laminar flow regime, at very low Reynolds numbers, approximately 30 minutes was required to reach 
steady-state conditions. As the mass flow rate was increased, the time required for steadystate decreased to 20 minutes. Although the mass flow rates in the transitional flow regime were greater than in the laminar flow regime, up to 1 hour was required to reach steady-state due to the mass flow rate and temperature fluctuations inside the tube. In the quasi-turbulent and turbulent flow regimes, approximately 15 minutes was required for steady-state. Data were only captured once steady-state conditions were obtained.

According to Olivier and Meyer [37] and Meyer [58], the effects of hysteresis were negligible in the transitional flow regime; therefore, the experiments were only conducted for increasing Reynolds numbers. Due to the large amount of data points, as well as the time required to reach steady-state, the experiments were divided into two categories: experiments were first conducted for laminar and transitional flow between Reynolds numbers of 500 and 4000 , and then for transitional, quasi-turbulent and turbulent flow between Reynolds numbers of 2000 and 10000 . The experiments started at the minimum mass flow rate (corresponding to $R e=500$ or $R e=2000$ ) and ended at the maximum flow rate (corresponding to $R e=4000$ or $R e=10000$ ). The Reynolds number was increased by increasing the mass flow rate using the frequency drives connected to the pumps. The supply and bypass valves were continuously adjusted to ensure that pumps operated close to their maximum speeds, to reduce mass flow rate pulsations. Different heat fluxes were applied to the test section by adjusting the applied voltage of the power supplies. After steady-state had been reached, 200 measuring points (temperature, pressure and mass flow rate) were captured at a frequency of $10 \mathrm{~Hz}$. The average value of the 200 measuring points was then used in the calculations.

The thermocouples and pressure transducers were re-calibrated every six months to prevent any experimental drift, and the differences between the calibration factors were insignificant. Statistical significant experiments were conducted three years later after the initial experiments and compared well with the initial measurements. Therefore, no significant drift in the instrumentation and experiments occurred.

\section{Test matrix}

Table 1 summarises the experiments conducted at different mass flow rates and heat fluxes in the two test sections of $11.5 \mathrm{~mm}$ and $4 \mathrm{~mm}$. The test matrix consisted of 1046 mass flow rate measurements, 89459 temperature measurements and 2906 pressure drop measurements. 
Table 1: Experimental test matrix generated with water in $4 \mathrm{~mm}$ and $11.5 \mathrm{~mm}$ test sections.

\begin{tabular}{cccccc}
\hline $\begin{array}{c}\text { Test } \\
\text { section }\end{array}$ & $\begin{array}{c}\text { Heat flux } \\
{\left[\mathrm{kW} / \mathrm{m}^{2}\right]}\end{array}$ & $\begin{array}{c}\text { Reynolds } \\
\text { number range }\end{array}$ & $\begin{array}{c}\text { Mass flow rate } \\
\text { measurements }\end{array}$ & $\begin{array}{c}\text { Temperature } \\
\text { measurements* }\end{array}$ & $\begin{array}{c}\text { Pressure drop } \\
\text { measurements }\end{array}$ \\
\hline \multirow{5}{*}{$11.5 \mathrm{~mm}$} & 0 & $507-14968$ & 178 & 16535 & 1095 \\
& 0.06 & $303-1793$ & 28 & 1344 & - \\
& 1 & $597-9280$ & 69 & 7521 & 552 \\
& 2 & $894-9376$ & 62 & 6758 & 496 \\
& 6.5 & $1061-9509$ & 55 & 5995 & 440 \\
& 8 & $460-9630$ & 111 & 5382 & 111 \\
$4 \mathrm{~mm}$ & 9.5 & $470-9600$ & 103 & 4944 & 103 \\
& 0.5 & $913-3303$ & 32 & 5232 & 109 \\
\hline & 1 & $965-6021$ & 67 & 3456 & - \\
& 2 & $947-7176$ & 66 & 7236 & - \\
& 4 & $1005-6963$ & 62 & 6128 & - \\
\hline
\end{tabular}

*3 or 4 thermocouples per station

For a part of this study, experimental results from literature [41, 53, 55, 59-61] were used. The difference between the results of this study and literature is that the Prandtl number in this study varied between 3 and 7, while the Prandtl number of the experiments conducted in literature was significantly higher (up to Prandtl numbers of 285). This study, together with those literature, therefore ensure that a wider range of Prandtl number data was available to use for interpretation and the development of correlations.

Table 2: Experimental test matrix of studies from literature.

\begin{tabular}{cccccc}
\hline \multirow{2}{*}{ Study } & \multicolumn{3}{c}{ Estimated number of mass flow rate measurements } & \multirow{2}{*}{$\operatorname{Pr}$} \\
\cline { 2 - 5 } & Laminar & Transitional & Turbulent & Total & \\
\hline Meyer et al. [41] & 30 & 86 & 150 & 266 & $6-9$ \\
Meyer and Abolarin [44] & 32 & 30 & 154 & 216 & $3-7$ \\
Kupper [59] & 22 & - & - & 22 & $4-9$ \\
Chen [60] & 33 & 10 & 5 & 48 & $4-285$ \\
Strickland [61] & 13 & 37 & 32 & 82 & $3-158$ \\
Meyer and Tang [62] & 34 & - & - & 34 & 35 \\
\hline
\end{tabular}

\section{Validation}

Extensive validation experiments were conducted and the details are given in Everts [57]. The heat transfer validation consisted of local laminar Nusselt numbers for forced and mixed convection conditions, as well as average laminar and turbulent Nusselt number validations. The pressure drop validation consisted of isothermal friction factor validations of developing

\footnotetext{
${ }^{1}$ These experiments were conducted in the same laboratory at the University of Pretoria, under the supervision of the first author. Grote and Abolarin were both graduate students.
} 
and fully developed flow in the laminar and turbulent flow regimes. The details of the local laminar Nusselt number validation for forced and mixed convection conditions are given in this paper, since these validations were specifically relevant to the results in this paper.

\subsection{Local laminar Nusselt numbers (forced convection)}

For fully developed laminar flow in a circular smooth tube with a constant heat flux boundary condition, literature dictates that the Nusselt number should be 4.36 [63], which is indicated by the black dotted line in Fig. 3. The local Nusselt numbers at a Reynolds number of 941 and heat flux of $60 \mathrm{~W} / \mathrm{m}^{2}$ are represented by the blue markers in Fig. 3. The average fully developed Nusselt number $(50<x / D<827)$ was 4.75 , which is within $8.9 \%$ of the theoretical Nusselt number of 4.36. The local Nusselt numbers also correlated well with the equation of Shah and London [11] for simultaneously thermally and hydrodynamically developing flow, with an average deviation of $19 \%$, while the deviation between $x / D=567$ and $x / D=724$ was less than $3 \%$. The local surface temperatures, measured by the thermocouples at a station, were also checked (especially comparing the temperatures at the top to the temperatures at the bottom) and the average deviation between the temperature measurements was calculated to be $0.04^{\circ} \mathrm{C}$. This was within the uncertainty range of the thermocouples and it could therefore be concluded that fully developed forced convection conditions were successfully obtained in the laminar flow regime.

Although the uncertainty was very high $(56 \%)$ at the first thermocouple station (due to the very small surface-fluid temperature difference), it decreased along the test section to a minimum of $30 \%$. The thermocouple uncertainty was $0.1{ }^{\circ} \mathrm{C}$, while the surface-fluid temperature difference at the first thermocouple station was only $0.16^{\circ} \mathrm{C}$, and increased along the test section to $0.2^{\circ} \mathrm{C}$. Furthermore, the difference between the inlet and outlet temperatures across the tube length of $9.5 \mathrm{~m}$ was $0.63^{\circ} \mathrm{C}$, and the average surface-fluid temperature only $0.23^{\circ} \mathrm{C}$. It was therefore very challenging to experimentally obtain forced convection conditions with low uncertainties, which might explain why so little experimental data is available in literature that shows forced convection conditions. 


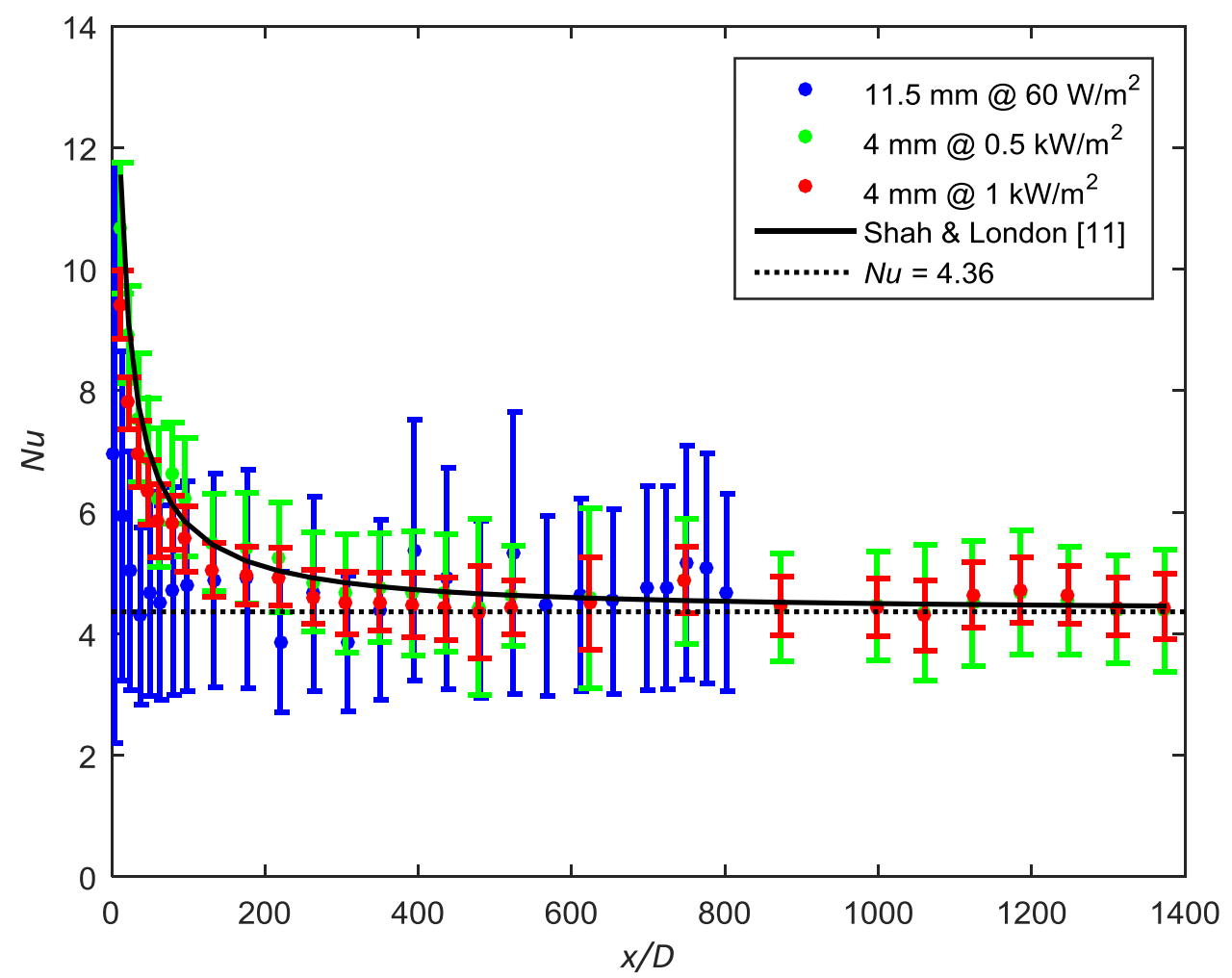

Fig. 3: Comparison with literature of local laminar forced convection Nusselt numbers as a function of axial position. The $60 \mathrm{~W} / \mathrm{m}^{2}$ results in the $11.5 \mathrm{~mm}$ test section are at an average Reynolds number of 941 , average Grashof number of $1.67 \times 10^{4}$ and average Prandtl number of 6.75 . The $1 \mathrm{~kW} / \mathrm{m}^{2}$ results in the $4 \mathrm{~mm}$ test section are at an average Reynolds number of 965, average Grashof number of 253 and average Prandtl number of 6.0.

As the diameter of the $11.5 \mathrm{~mm}$ test section was 2.88 times greater than the $4 \mathrm{~mm}$ test section, the Grashof number, and thus free convection effects, can be expected to be approximately 24 times fewer in the $4 \mathrm{~mm}$ test section $\left(G r \propto D^{3}\right)$. A higher heat flux (and thus decreased uncertainties) could therefore be applied, while still obtaining forced convection conditions. The local Nusselt numbers at an average Reynolds number of 1000 were compared for heat fluxes of $0.5 \mathrm{~kW} / \mathrm{m}^{2}$ (green markers) and $1 \mathrm{~kW} / \mathrm{m}^{2}$ (red markers) in Fig. 3. From this figure it follows that there was no significant difference between the Nusselt numbers of the two heat fluxes, which confirms that free convection effects were negligible. The average Nusselt number between $x / D=873$ and $x / D=1373$ was 4.46 at a heat flux of $0.5 \mathrm{~kW} / \mathrm{m}^{2}$, and 4.58 at a heat flux of $1 \mathrm{~kW} / \mathrm{m}^{2}$, which was within $2.3 \%$ and $5 \%$ of the theoretical Nusselt number of 4.36. Fully developed forced convection conditions were thus successfully obtained. However, the uncertainties were lower at a heat flux of $1 \mathrm{~kW} / \mathrm{m}^{2}$, due to the increased temperature differences. It was therefore decided to use a heat flux of $1 \mathrm{~kW} / \mathrm{m}^{2}$ in the $4 \mathrm{~mm}$ test section for the forced convection investigation. The results 
also correlated very well with the correlation of Shah and London [11] with an average deviation of $1.7 \%$.

Of the 891 fully developed laminar experimental data points in the $4 \mathrm{~mm}$ and $11.5 \mathrm{~mm}$ test sections, it was found that forced convection conditions existed in only $5.4 \%$ of all the experiments, since the fully developed Nusselt number was within $10 \%$ of the theoretical fully developed Nusselt number of 4.36. A Nusselt number increase of less than $20 \%$ and $50 \%$ was obtained in only $13 \%$ and $24 \%$ of the data, respectively, while an increase of $100 \%$ or more was found in more than $60 \%$ of the data. It can thus be concluded that it is very challenging to experimentally obtain forced convection conditions. Forced convection conditions in the laminar flow regime could only be validated in this study at very low heat fluxes for 21 different mass flow rates. Therefore, in most experiments, not only from this study, but also from literature summarised in Table 2, mixed convection conditions occurred rather than forced convection.

\subsection{Local laminar Nusselt numbers (mixed convection)}

To validate the local laminar Nusselt numbers for mixed convection conditions, experiments were conducted in the $11.5 \mathrm{~mm}$ test section at a heat flux of $1 \mathrm{~kW} / \mathrm{m}^{2}$ and a bulk Reynolds number of 941. Experiments were also conducted in the $4 \mathrm{~mm}$ test section at a Reynolds number of 1005 and heat flux of $3 \mathrm{~kW} / \mathrm{m}^{2}$. The results in both test sections were compared with the correlation of Morcos and Bergles [55]. The heat transfer coefficients in the laminar flow regime were very sensitive to the heating or cooling methodology, Prandtl number, forced and mixed convection conditions, as well as developing and fully developed flow. It was found that limited correlations were available from literature which were suitable for the conditions (developing mixed convection laminar flow with low Prandtl numbers) of this study. The only correlation available that partially suited the parameter ranges (only the tube wall parameter was not within the specified ranges) of this study was the correlation of Morcos and Bergles [55].

From Fig. 4, it follows that the Nusselt numbers in both test sections correlated well with the correlation of Morcos and Bergles [55]. The average deviation between $x / D=37$ and $x / D=827$ in the $11.5 \mathrm{~mm}$ test section was $6 \%$, while the average deviation between $x / D=79$ and $x / D=1373$ in the $4 \mathrm{~mm}$ test section was $4 \%$. Exact correlation was not expected since the range of the tube wall parameter in the Morcos and Bergles [55] correlation was between 2 and 66, while it was approximately 0.03 and 0.15 in the $11.5 \mathrm{~mm}$ and $4 \mathrm{~mm}$ test sections, respectively, during this validation. Furthermore, this correlation was developed for fully 
developed flow, while developing flow existed near the inlet of the test section. However, all the other parameters were within the specified ranges of the correlation.

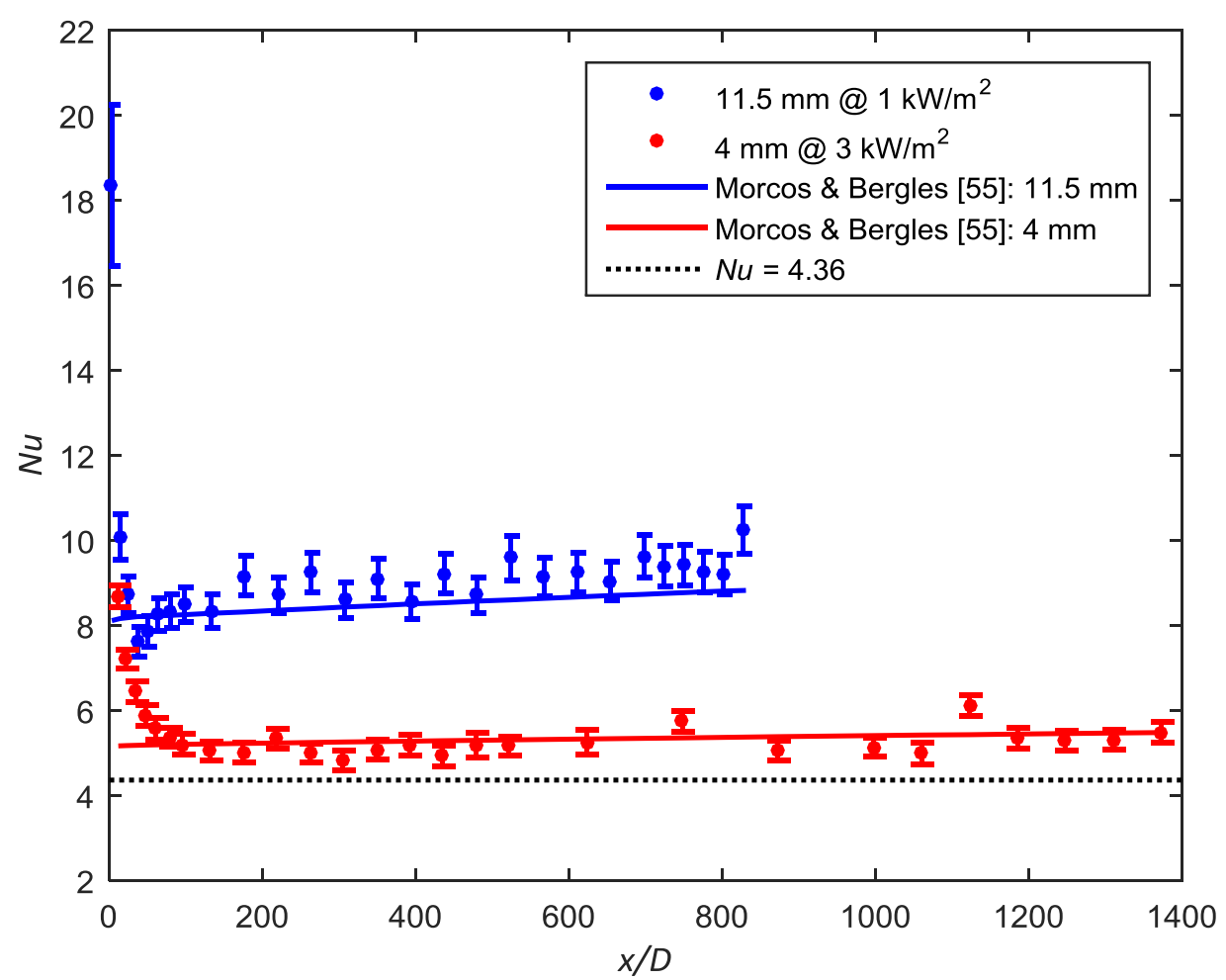

Fig. 4: Comparison with literature of local laminar mixed convection Nusselt numbers as a function of axial position. The results in the $11.5 \mathrm{~mm}$ test section is at an average Reynolds number of 941 , average Grashof number of $1.04 \times 10^{5}$ and average Prandtl number of 5.9. The results in the $4 \mathrm{~mm}$ test section is at an average Reynolds number of 1005 , average Grashof number of $1.1 \times 10^{5}$ and average Prandtl number of 4.9 .

\section{Heat transfer regions for laminar and transitional flow}

It has been found from analysing the experimental data of this study and literature [41, 44], that all mixed convection data in the laminar and transitional flow regimes could be represented as shown schematically in Fig. 5. It shows the effect of Grashof number (free convection effects) on the local Nusselt numbers, as a function of axial position, in the laminar flow regime (Fig. 5(a)), on the critical Reynolds number (Fig. 5(b)), and on the laminar-turbulent transition for mixed convection conditions in the transitional flow regime (Fig. 5(d)). The effect of Reynolds number on the laminar-turbulent transition for forced convection conditions in the transitional flow regime, is schematically illustrated in Fig. 5(c).

In Fig. 5(a), (b) and (d), the red line, 1, represents forced convection conditions, while lines 2 to 4 represent increasing values of Grashof number (thus increased free convection effects). However, in Fig. 5(c), the red dashed line, 1, represents the critical Reynolds number, while lines 2 to 4 represent increasing values of Reynolds number. Furthermore, 
three different regions were identified in the laminar flow regime (Fig. 5(a)): Forced Convection Developing (FCD), Mixed Convection Developing (MCD) and Fully Developed (FD). When the Reynolds number exceeded the critical Reynolds number, four different regions were identified in the transitional flow regime (Fig. 5(c) and (d)): laminar, transition, quasi-turbulent and turbulent. However, these regions could not be identified at the critical Reynolds number (Fig. 5(b)). The names of these four flow regions were based on the four flow regimes identified and quantified by Everts and Meyer [45].

The trends shown in Fig. 5 are supported by experimental data in Sections 9 and 11. The reasons why only the trends are shown schematically and not according to scale are: (1) the laminar results of the different Grashof numbers in the FCD region are very close to each other, and (2) the FCD region forms only a small part of the tube length, which makes it difficult to identify the trends. This was also true for (3) the Nusselt numbers near the inlet of the test section in the transitional flow regime. It has also been found that in the transitional flow regime, (4) the laminar-turbulent-transition, is very dependent on Reynolds number and Grashof number, which made it challenging to obtain and compare results for different Grashof numbers at a fixed Reynolds number, and vice versa. Furthermore, (5) some scatter existed in the experimental data, which made it challenging to illustrate clear trends.

\subsection{Laminar flow regime (Fig. 5(a))}

If the Grashof number is so low that the flow can be considered as forced convection, the results will follow the red forced convection line. As the flow develops axially from the tube inlet, all the results initially follow the red forced convection line. When the Grashof number is increased, free convection effects become significant and the results break away from the red line. Furthermore, as indicated by points D, G and $\mathrm{J}$, the axial position at which the results break away from the red line (FCD/MCD) decreases with increasing Grashof number. 


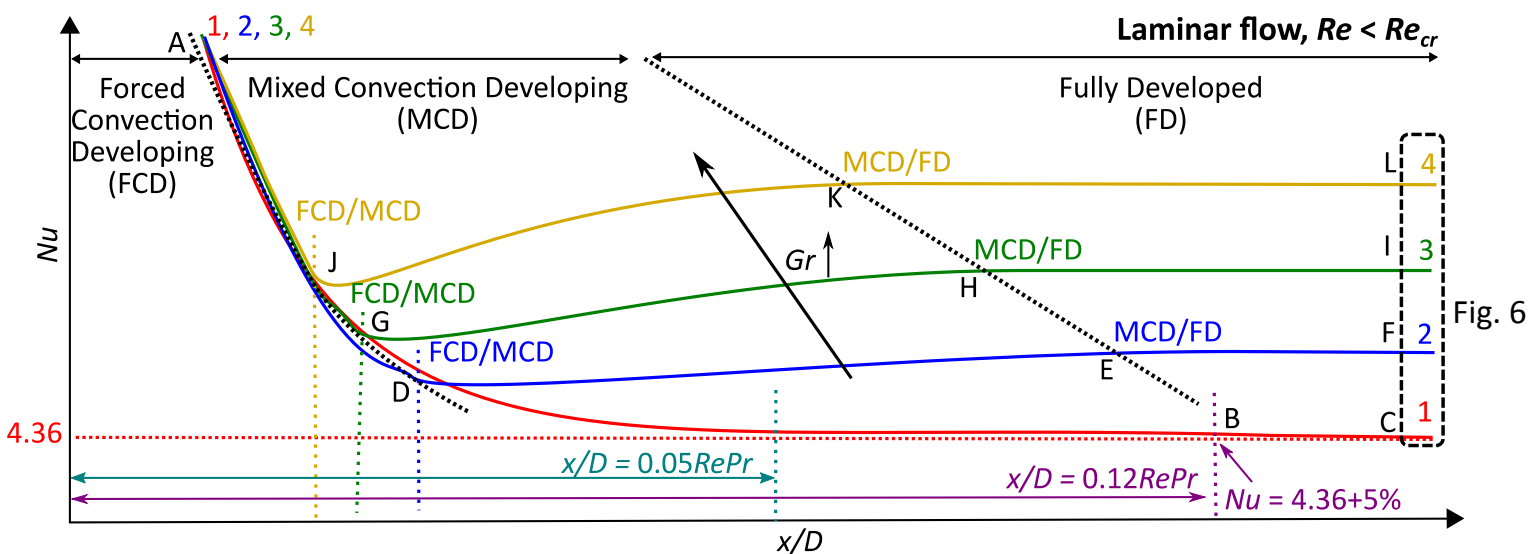

(a)

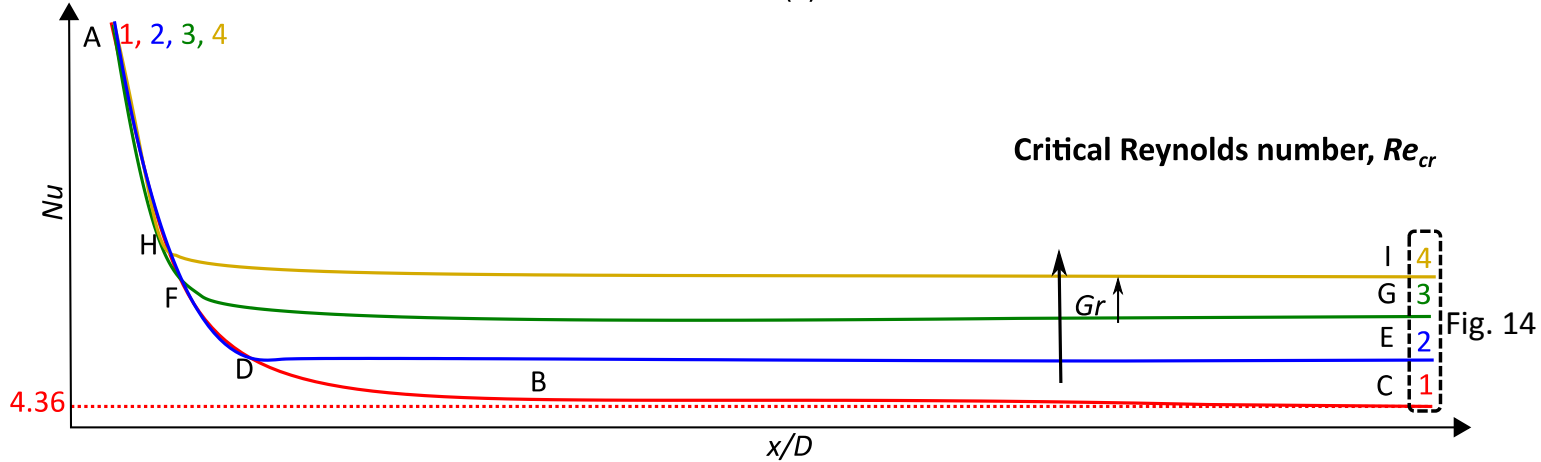

(b)

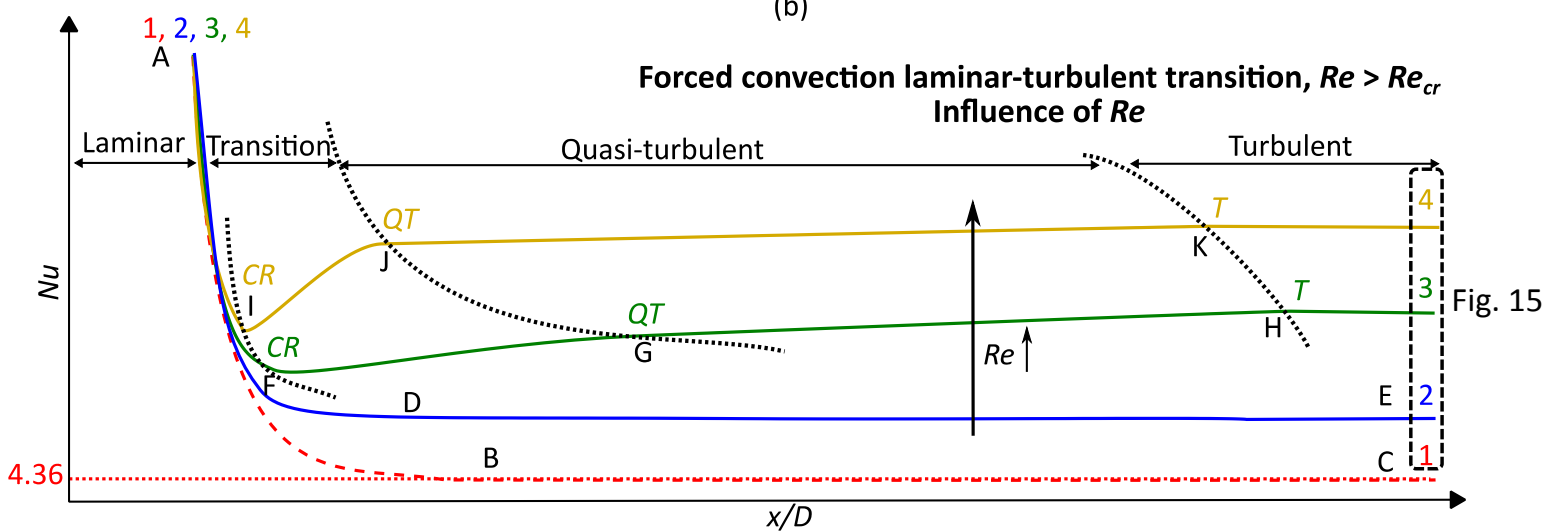

(c)

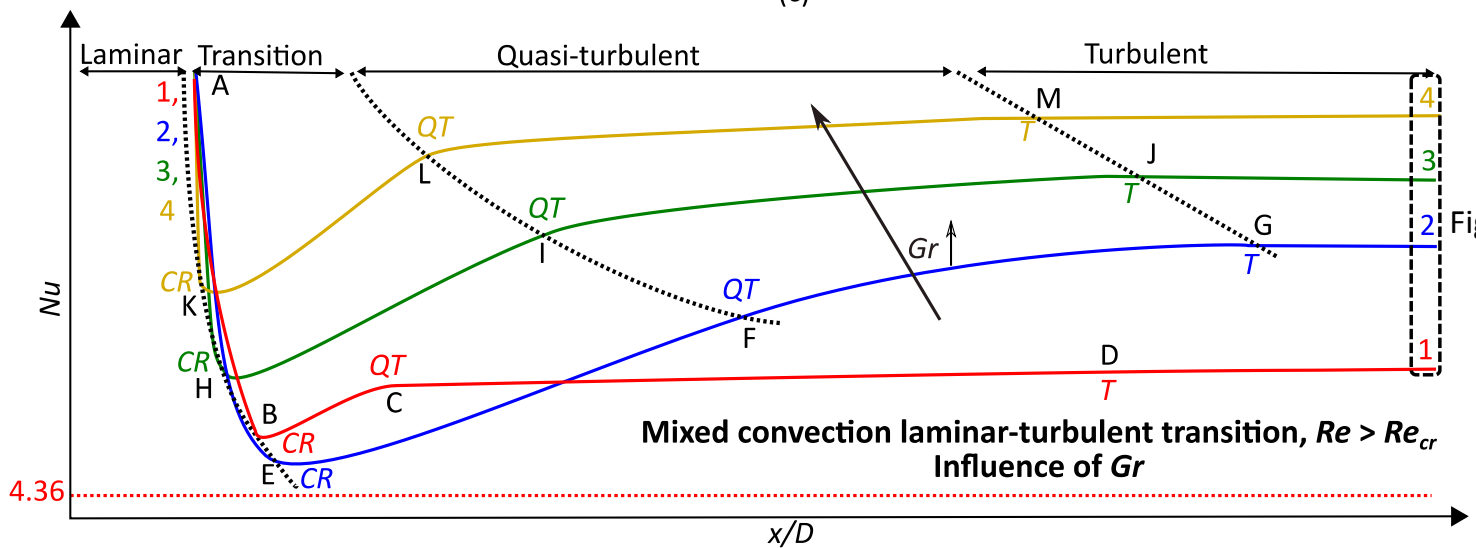

(d)

Fig. 5: Schematic representation of the developing Nusselt numbers showing the effects of (a) Grashof number in the laminar flow regime, (b) Grashof number at the critical Reynolds number, (c) Reynolds number on the forced convection laminar-turbulent transition and (d) Grashof number on the mixed convection laminar-turbulent transition. 
In the Forced Convection Developing (FCD) region, the gradient of the Nusselt number lines decreases slightly with increasing Grashof number, since the thermal entrance length decreases. However, this difference is very small since free convection effects are negligible in this region. In the Mixed Convection Developing (MCD) region, the Nusselt numbers increase along the tube length, since the flow develops and free convection effects increase. As indicated by lines D-E, G-H and J-K, the gradient of the Nusselt number lines increases with Grashof number.

For forced convection conditions, the flow is considered as fully developed when the Nusselt numbers are within $5 \%$ of the theoretical Nusselt number of 4.36 , and becomes constant. For simultaneously hydrodynamically and thermally developing flow (refer to Section 9.2), this value corresponds to $x / D=0.12 \operatorname{Re} \operatorname{Pr}$ (indicated by the purple dotted line) and not $x / D=0.05 \operatorname{RePr}$ (indicated by the teal dotted line). As indicated by points $\mathrm{E}, \mathrm{H}$, and $\mathrm{K}$, the axial position at which the flow becomes fully developed decreases with increasing Grashof number. In the Fully Developed (FD) region, the Nusselt numbers and free convection effects are constant along the tube length, since the flow is fully developed. However, the magnitude of the Nusselt numbers increases with increasing Grashof number (points C, F, I and L).

\subsection{Critical Reynolds number (Fig. 5(b))}

At the critical Reynolds number, the local Nusselt numbers decrease along the tube length near the inlet of the test section, and then become constant. No MCD regions (Fig. 5(a)) were observed. As the thermal entrance length decreases with increasing Grashof number, the Nusselt number gradients near the inlet of the test section (A-D, A-F and A-H) decrease and the Nusselt numbers become constant earlier along the tube length (points B, D, F and H). The Nusselt numbers remain constant further along the tube length. However, the magnitude of the Nusselt numbers increased with increasing Grashof numbers (points C, E, G and I).

\subsection{Forced convection laminar-turbulent transition (Fig. 5(c))}

When the Reynolds number exceeds the critical Reynolds number and the flow is in the transitional flow regime, laminar-turbulent transition occurs along the tube length. When forced convection conditions exist and the Reynolds number is increased above the critical Reynolds number (red and blue lines), the trends are similar. However, the axial position at which the Nusselt numbers become constant, decreases (points B and D), and the magnitude of the Nusselt numbers increases (points $\mathrm{C}$ and $\mathrm{E}$ ) due to the increased fluid velocity. The 
increased fluid velocity enhances mixing inside the test section, therefore the Nusselt numbers increase.

As the Reynolds number is increased further (green and yellow lines), four regions (laminar, transition, quasi-turbulent and turbulent) can be identified. The heat transfer characteristics in the laminar region are similar to those of the laminar FCD region (Fig. 5(a)). Therefore, the gradient of the Nusselt number lines in the laminar region (lines A-F and A-I) decrease with increasing Reynolds number, since the thermal entrance length increases.

The axial position at which the Nusselt numbers start to increase (points $F$ and I), decreases with increasing Reynolds number. In the transitional flow regime, fluctuations occur inside the test section since the flow alternates between laminar and turbulent flow. These fluctuations increase along the tube length [45], which lead to increased mixing, therefore enhanced heat transfer and increased Nusselt numbers. The gradient of the Nusselt numbers (lines F-G and I-J) increases with increasing Reynolds number, which implies that the transition from the laminar to the quasi-turbulent regions, occurs faster (points $\mathrm{G}$ and $\mathbf{J}$ ) and the transition region decreases.

In the quasi-turbulent region, the flow characteristics are similar to turbulent flow, however the flow is not yet turbulent, and the local Nusselt numbers increase along the tube length. The gradient of the Nusselt number lines in the quasi-turbulent region (lines $\mathrm{G}-\mathrm{H}$ and $\mathrm{J}-\mathrm{K})$ decrease with increasing Reynolds number, and approach zero as the flow approaches the turbulent region. The axial position at which the Nusselt numbers become constant (points $\mathrm{H}$ and $\mathrm{K}$ ) also decreases with increasing Reynolds number. However, as this decrease is less than for points $\mathrm{G}$ and $\mathrm{J}$, the width of the quasi-turbulent region increases slightly with increasing Reynolds number. The magnitude of the Nusselt numbers in the quasi-turbulent and turbulent regions increases with increasing Reynolds number, due to the enhanced mixing inside the tube.

\subsection{Mixed convection laminar-turbulent transition (Fig. 5(d))}

When mixed convection conditions exist, the Nusselt numbers decrease along the tube length near the inlet of the test section. The axial position at which the Nusselt numbers start to increase (points $\mathrm{E}, \mathrm{H}$ and $\mathrm{K}$ ), decreases with increasing Grashof number and the gradient of the Nusselt number lines in the transition region (lines E-F, H-I and K-L) increases. Therefore, the width of the transition region decreases with Grashof number. In the quasiturbulent region, the gradient of the Nusselt number lines (lines F-G, I-J and L-M) decreases 
with increasing Grashof number, and the magnitude of the Nusselt numbers increases. The axial position at which the Nusselt numbers become constant (points G, J and M), decreases with increasing Grashof number. The Nusselt numbers in the turbulent region remain constant along the tube length. However, it increases with increasing Grashof number.

Although the laminar-turbulent transition occurs faster with increasing Grashof number when the flow is dominated by mixed convection (blue, green and yellow lines), a different trend was observed when free convection effects first become significant at very low Grashof numbers (red and blue lines). As free convection effects become significant, the effect is to first disturb the fluctuations inside the test section and cause transition to occur slower (compared to forced convection conditions), therefore the free convection effects have a dampening effect. However, as the Grashof number is increased, the fluctuations inside the test section increase significantly with increasing free convection effects [45], which cause the flow to transition faster from laminar to turbulent.

\section{Results: Laminar flow}

The results in this section are directly aligned to Fig. 5(a). Points A-L in Fig. 6, Fig. 8, Fig. 9 and Fig. 10, correspond to the labels used in Fig. 5(a).

\subsection{Local Nusselt numbers}

To investigate the effect of free convection on the local laminar Nusselt numbers, the Nusselt numbers as a function of axial position at a Reynolds number of approximately 1800 are compared for different heat fluxes and tube diameters (cf. Fig. 6). Also included is the experimental data at a heat flux of $4 \mathrm{~kW} / \mathrm{m}^{2}$ in a $19 \mathrm{~mm}$ test section [44]. The solid markers represent the results (at different heat fluxes) in the $4 \mathrm{~mm}$ test section, while the star and square markers represent the results in the $11.5 \mathrm{~mm}$ and $19 \mathrm{~mm}$ test sections, respectively. The correlation of Shah and London [11], which is valid for simultaneously hydrodynamically and thermally developing forced convection flow, is indicated by the solid red line, while the theoretically fully developed forced convection Nusselt number of 4.36, is indicated by the horizontal red dotted line. The vertical black dotted line indicates the fully developed flow condition of $1 / G z \geq 0.05$ (Eq. (1)).

As expected, the maximum Nusselt numbers were found at the inlet of the test section, since the thickness of the thermal boundary layer was a minimum. It then decreased along line A-B-C, as the thermal boundary layer thickness increased and the flow approached fully developed flow. The forced convection data is indicated by the black markers and 
corresponds very well with the correlation of Shah and London [11] (red line in Fig. 6). This formed the "lower boundary" of the local Nusselt numbers and corresponds to the red line in Fig. 5(a).

As the heat flux in the $4 \mathrm{~mm}$ test section was increased, the Nusselt numbers began to increase and deviate from this line (point D), since free convection effects became significant. This trend is illustrated by the red and blue lines in Fig. 5(a). From points D, G and $\mathrm{J}$ in Fig. 6 (and schematically illustrated in Fig. 5(a)), it follows that as the Grashof number was increased further by increasing the tube diameter and heat flux, free convection effects caused the local Nusselt numbers to deviate from the forced convection results earlier along the test section. Furthermore, the gradient of the Nusselt number lines near the inlet of the test section (A-G and A-J) decreased with increasing Grashof number. Therefore, free convection effects caused the Nusselt numbers to develop faster along the tube length.

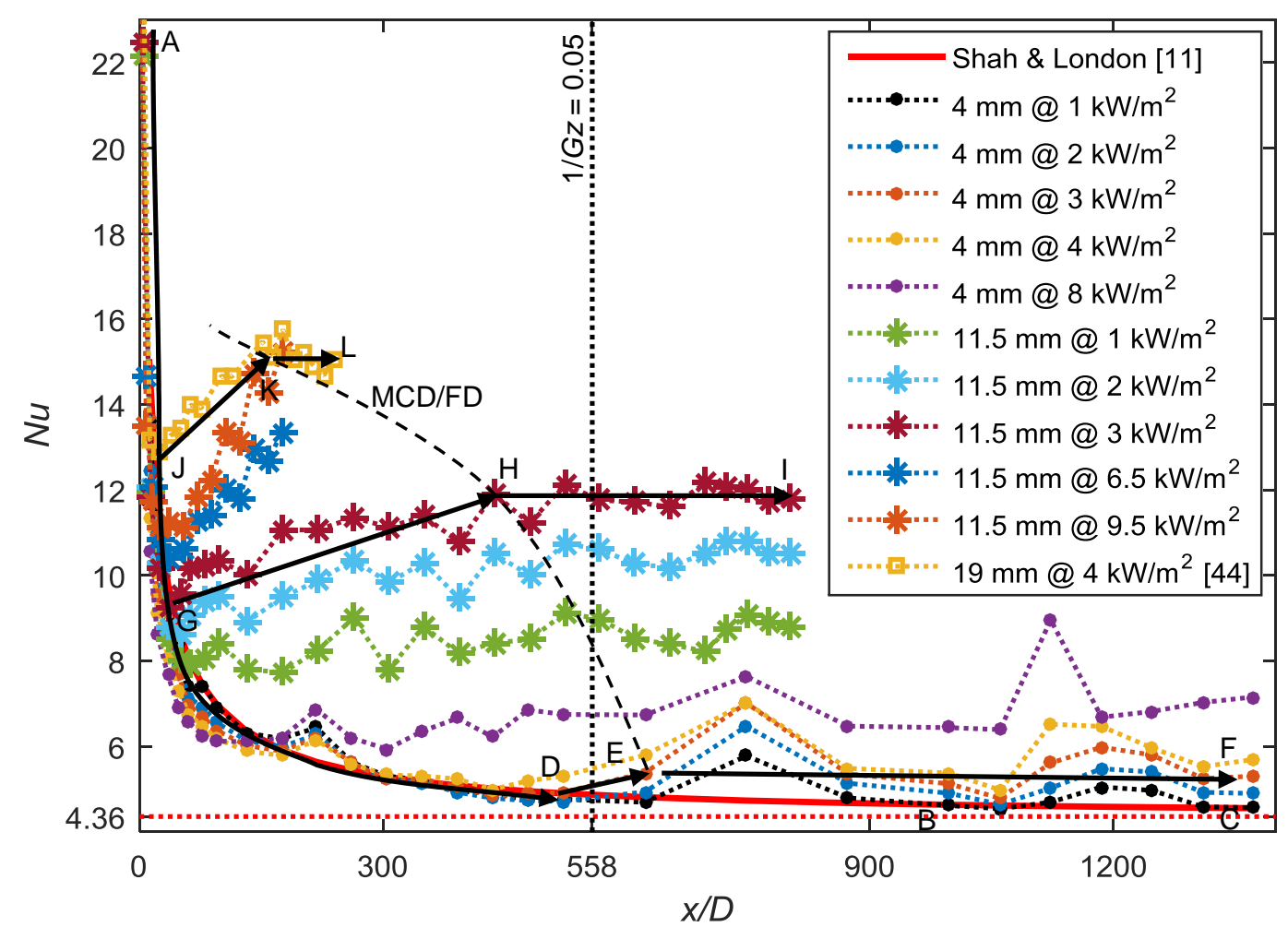

Fig. 6: Comparison of Nusselt numbers as a function of axial position, at a Reynolds number of 1800 for different heat fluxes and tube diameters using water as the test fluid. Also included is the experimental data at a heat flux of $4 \mathrm{~kW} / \mathrm{m}^{2}$ in a $19 \mathrm{~mm}$ test section [44]. The solid markers represent the results (at different heat fluxes) in the $4 \mathrm{~mm}$ test section, while the star and square markers represent the results in the $11.5 \mathrm{~mm}$ and $19 \mathrm{~mm}$ test sections, respectively. The forced convection results are indicated by points A-B-C along the solid red line. Arrows A-D-E-F and A-G-H-I indicate the trend at a heat flux of $3 \mathrm{~kW} / \mathrm{m}^{2}$ in the $4 \mathrm{~mm}$ and $11.5 \mathrm{~mm}$ test sections, while arrows A-J-K-L indicate the trend at a heat flux of $4 \mathrm{~kW} / \mathrm{m}^{2}$ in the $19 \mathrm{~mm}$ test section.

As schematically illustrated in Fig. 5(a), it follows from arrows D-E, G-H and J-K in Fig. 6 , that as the heat flux and tube diameter were increased, the magnitude and gradient of the 
Nusselt numbers increased. This can be expected since the Grashof number, and thus free convection effects, increased with increasing heat flux and tube diameter, which led to enhanced heat transfer inside the test section, and thus increased Nusselt numbers.

Therefore, unlike the forced convection results, the local Nusselt numbers did not decrease and became constant, but decreased to a minimum and then began to increase before they became constant and the flow fully developed. This is due to the combined effects of free convection and developing flow. A similar trend was observed by Cheng and Ou [23] who explained that the local Nusselt numbers decreased near the inlet due to the entrance effect, and free convection effects were negligible. At the minimum Nusselt number (for example points D, G and J in Fig. 6), the entrance and free convection effects were equal, but then the Nusselt numbers began to increase once the free convection effects began to dominate the entrance effects. As the flow was not yet fully developed when it began to deviate from the forced convection line, free convection effects increased along the tube length [45], which caused the Nusselt numbers to increase along the tube length.

The Nusselt numbers became constant once the flow was fully developed and the surfacefluid temperature difference became constant (for example points E, H and K in Fig. 5(a) and Fig. 6). From points $\mathrm{E}, \mathrm{H}$ and $\mathrm{K}$ in Fig. 6, it follows that thermal entrance length decreased significantly with increasing Grashof number, since the Nusselt numbers became constant earlier along the test section. This trend is indicated by the black dotted MCD/FD-line in Fig. 5(a) and Fig. 6. Furthermore, as schematically illustrated in Fig. 5(a), free convection effects also caused the magnitude of the fully developed Nusselt numbers to increase.

\subsection{Thermal entrance lengths}

Fig. 7 summarises the local Nusselt numbers as a function of the inverse of the Graetz number, for Reynolds numbers between 1000 and 2000 at a heat fluxes of $0.5 \mathrm{~kW} / \mathrm{m}^{2}$ (filled markers) and $1 \mathrm{~kW} / \mathrm{m}^{2}$ (empty markers) in the $4 \mathrm{~mm}$ test section. (Take note that the $11.5 \mathrm{~mm}$ experiments were not used in this graph, due to greater uncertainties than for the $4 \mathrm{~mm}$ test section.) The vertical black dotted line indicates the fully developed flow condition of $1 / G z \geq 0.05$ (Eq. (1)). Also included in this figure are the correlations of Siegel et al. [13] for hydrodynamically fully developed and thermally developing flow, and of Shah and London [11] for simultaneously hydrodynamically and thermally developing flow. The theoretical Nusselt number of 4.36 for fully developed forced convection laminar flow is indicated by the horizontal black dotted line, while a $5 \%$ and $10 \%$ increase from this Nusselt number are indicated by the horizontal blue and red dotted lines, respectively. 
As the correlation of Siegel et al. [13] was developed for hydrodynamically fully developed flow, the predicted Nusselt numbers were lower than for the correlation of Shah and London [11], since the flow developed faster. Siegel et al. [13] considered the flow to be fully developed once the local Nusselt numbers were within $5 \%$ of the theoretical fully developed Nusselt number for 4.36, and reported that this should occur at $1 / G z \geq 0.0425$ (as indicated in Fig. 7). From Fig. 7 it follows that the correlation of Shah and London [11] only crossed the $5 \%$-line at $1 / G z \approx 0.11$. As the flow in this study was also simultaneously hydrodynamically and thermally developing, the trend of the local Nusselt numbers correlated better with the correlation of Shah and London [11].

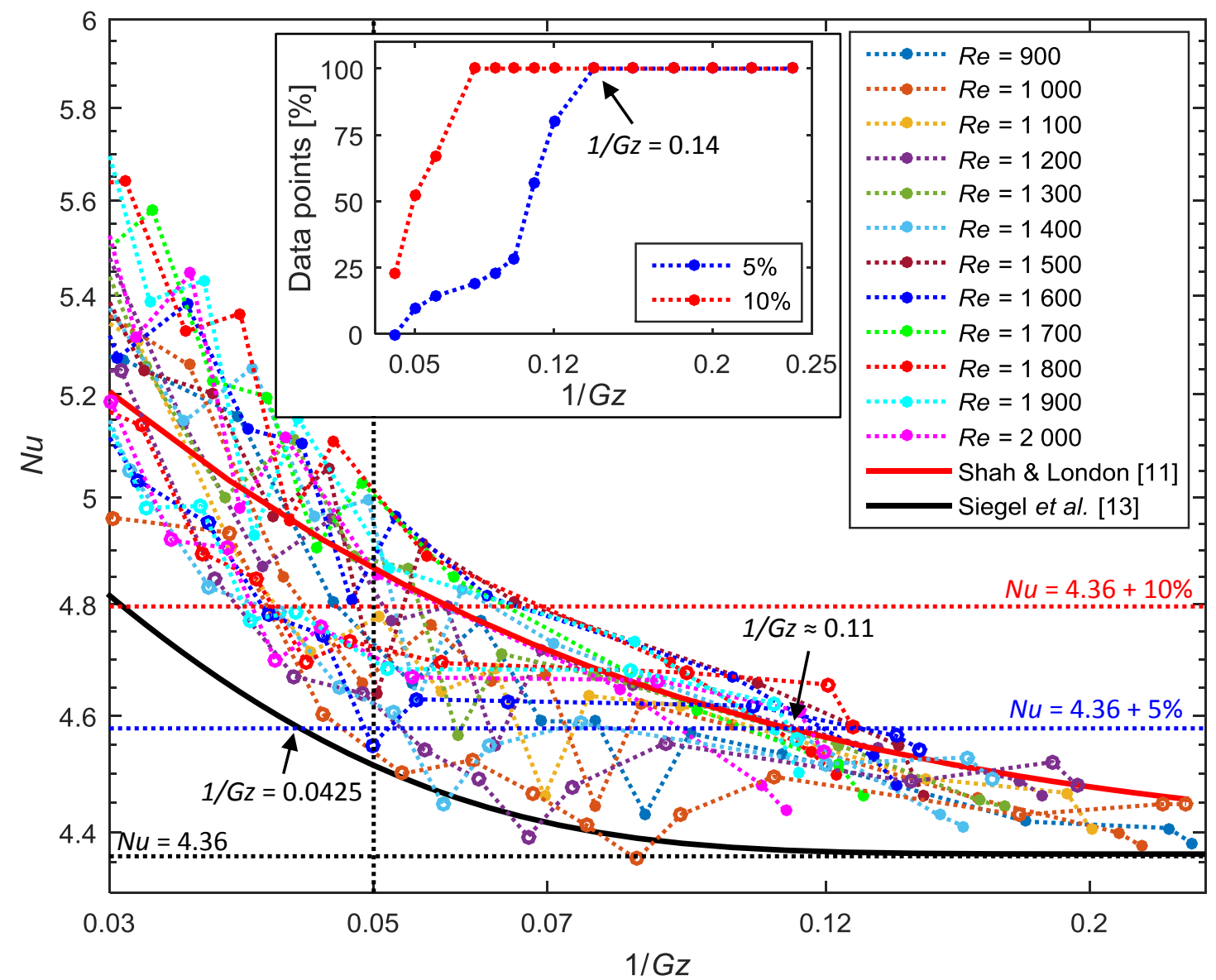

Fig. 7: Local Nusselt numbers as a function of the inverse of the Graetz number for Reynolds numbers between 900 and 2000 in the $4 \mathrm{~mm}$ test section. The filled and empty markers represent the results at heat fluxes of $0.5 \mathrm{~kW} / \mathrm{m}^{2}$ and $1 \mathrm{~kW} / \mathrm{m}^{2}$, respectively. The additional graph shows the percentage data points within $5 \%$ and $10 \%$ of the theoretical Nusselt number of 4.36 , as a function of the inverse of the Graetz number.

The additional graph in Fig. 7 shows the percentage data points within 5\% and $10 \%$ of the theoretical Nusselt number of 4.36 , as a function of $1 / G z$. From this graph it follows that at $1 / G z=0.05$, only $10 \%$ of the experimental data points were within $5 \%$ (thus fully 
developed). It therefore means that $C=0.05$ (Eq. (1)) as used in most subject literature, is inaccurate. At $1 / G z=0.12,80 \%$ of the experimental data points were within $5 \%$ and all the experimental data points within $10 \%$. This corresponds well to the value of $1 / G z \approx 0.11$ where the correlation of Shah and London [11] crossed the 5\%-line. At $1 / G z=0.14$, all the experimental data points were within 5\%. Acknowledging the uncertainty of our forced convection data (average uncertainty of $18 \%$ and $10 \%$ for heat fluxes of $0.5 \mathrm{~kW} / \mathrm{m}^{2}$ and $1 \mathrm{~kW} / \mathrm{m}^{2}$, respectively), we have found that $1 / G z \geq 0.12$ is a more accurate/conservative criterion for fully developed flow when the flow is simultaneously hydrodynamically and thermally developing. However, a conservative value of $1 / G z \geq 0.14$ will ensure that all the Nusselt numbers are within $5 \%$ of the theoretical Nusselt number of 4.36 . Furthermore, it can be concluded that the theoretical thermal entrance length correlation (Eq. (1)) is better suited for hydrodynamically fully developed flow, and that a longer thermal entrance length is required for simultaneously hydrodynamically and thermally developing flow, therefore a coefficient of 0.12 is recommended.

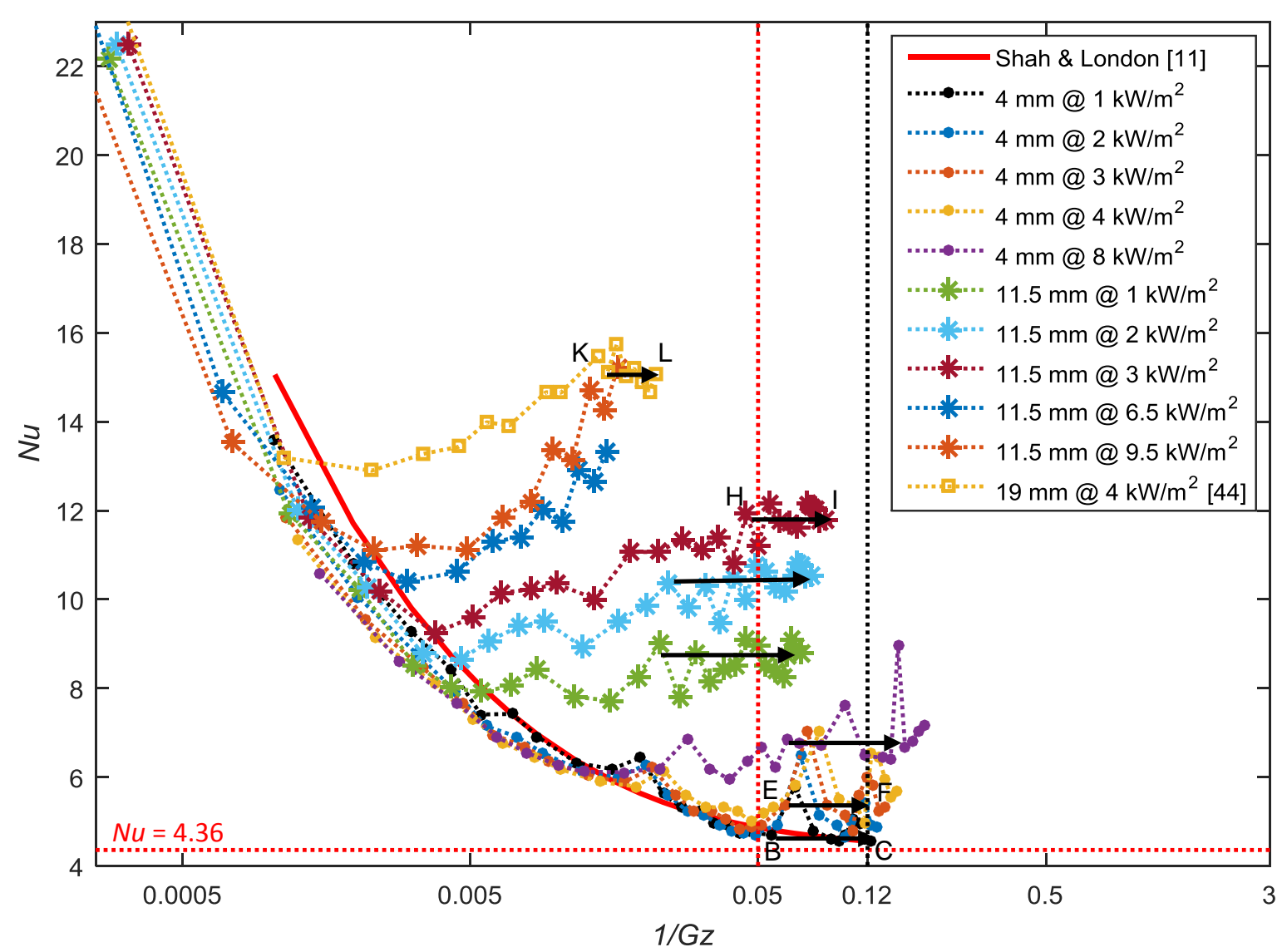

Fig. 8: Comparison of local Nusselt numbers against the inverse of the Graetz number, at a Reynolds number of 1800 for different heat fluxes and tube diameters. 
The mixed convection results in Fig. 6 are plotted against the inverse of the Graetz number in Fig. 8. The horizontal red dotted line represents the theoretical Nusselt number of 4.36 for fully developed forced convection laminar flow, while the vertical red dotted line indicates $1 / G z=0.05$, which is the thermal entrance length predicted using Eq. (1). The vertical black dotted line indicates $1 / G z=0.12$, which was the forced convection thermal entrance length for simultaneously hydrodynamically and thermally developing flow, found in Fig. 7.

The fully developed data are indicated using black horizontal arrows, and from these arrows it follows that, similar to Fig. 6 , the location $(1 / G z)$ at which the flow became fully developed decreased significantly with increasing tube diameter (thus increasing Grashof number). However, for a fixed tube diameter, the value of $1 / G z$ increased with increasing heat flux, since $1 / G z$ is inversely proportional to the Prandtl number which decreased with increasing temperature. As can be expected, it follows from Fig. 8 that both forced convection thermal entrance length conditions $(1 / G z=0.05$ and $1 / G z=0.12)$, became increasingly inaccurate at higher Grashof numbers $(11.5 \mathrm{~mm}$ test section and $19 \mathrm{~mm}$ test section) and should therefore be adjusted when mixed convection conditions exist, especially at high Grashof numbers.

\subsection{Boundaries between FCD, MCD and FD laminar regions}

For laminar flow, three different regions (FCD, MCD and FD in Fig. 5(a)) were identified and correlations were developed to quantify these FCD/MCD and MCD/FD boundaries. The ranges of the correlations are summarised in Table 3.

Table 3: Ranges of correlations to predict the FCD/MCD boundary (Eqs. (22) and (23)) and the MCD/FD boundary (Eqs. (24) and (25)).

\begin{tabular}{ccccccc}
\hline & $R e$ & $P r$ & $G r$ & $G r^{*}$ & $G z$ & $D[\mathrm{~mm}]$ \\
\hline FCD/MCD & \multirow{2}{*}{$48-3217$} & \multirow{2}{*}{$2.9-282$} & $2.48-$ & $541-$ & $2.6-$ & $3-19$ \\
$(22),(23)$ & & & $4.51 \times 10^{5}$ & $4.01 \times 10^{6}$ & $1.14 \times 10^{5}$ & $3-19$ \\
MCD/FD & $467-3217$ & \multirow{2}{*}{$2.9-53$} & $30.6-$ & $2.48-$ & $2.6-$ & $4-19$ \\
$(24),(25)$ & & & $4.51 \times 10^{5}$ & $6.02 \times 10^{5}$ & $3.49 \times 10^{4}$ & $4-19$ \\
\hline
\end{tabular}

\subsubsection{FCD/MCD boundary}

To determine the FCD/MCD boundary, the Nusselt numbers in Fig. 6 were evaluated in terms of $(1 / G z) G r^{0.57} \mathrm{Pr}^{0.4}$, to account for mixed convection conditions $(\mathrm{Gr})$ and different test fluids (Pr). From Fig. 9(a) it follows that the FCD/MCD boundary (points B, D, G and J) can 
be estimated to be at $(1 / G z) G r^{0.57} \operatorname{Pr}^{0.4}=C_{1}$, where the constant $C_{1}$ is approximately equal to 2.4 .

Using the boundary $(1 / G z) G r^{0.57} \operatorname{Pr}^{0.4}=C_{1}$, the entrance length required for the flow to be in the MCD region can be determined as follows, and can also be written as a function of the forced convection thermal entrance length, $L t_{F C}$, (using $C=0.12$ ):

$$
L t_{M C D}=\frac{C_{1} \operatorname{RePr}{ }^{0.6} D}{G r^{0.57}}=\frac{C_{1} L t_{F C}}{0.12 G r^{0.57} \operatorname{Pr}^{0.4}}
$$

From Eq. (22) it follows that similar to Eq. (1), the entrance length for mixed convection developing flow, $L t_{M C D}$, increased with increasing Reynolds number, Prandtl number and tube diameter. However, it was inversely proportional to the Grashof number and therefore decreased as free convection effects increased. Furthermore, the entrance length was a weaker function of Prandtl number (compared to forced convection) once free convection effects became significant. This was expected, since the fluid properties (density and viscosity) were accounted for in the Reynolds number and Grashof number.

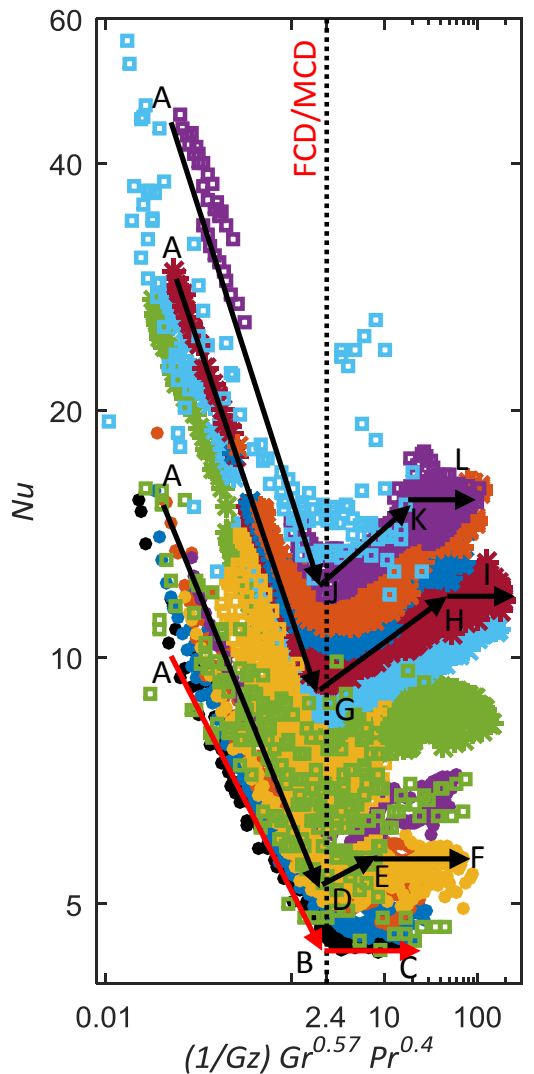

(a)

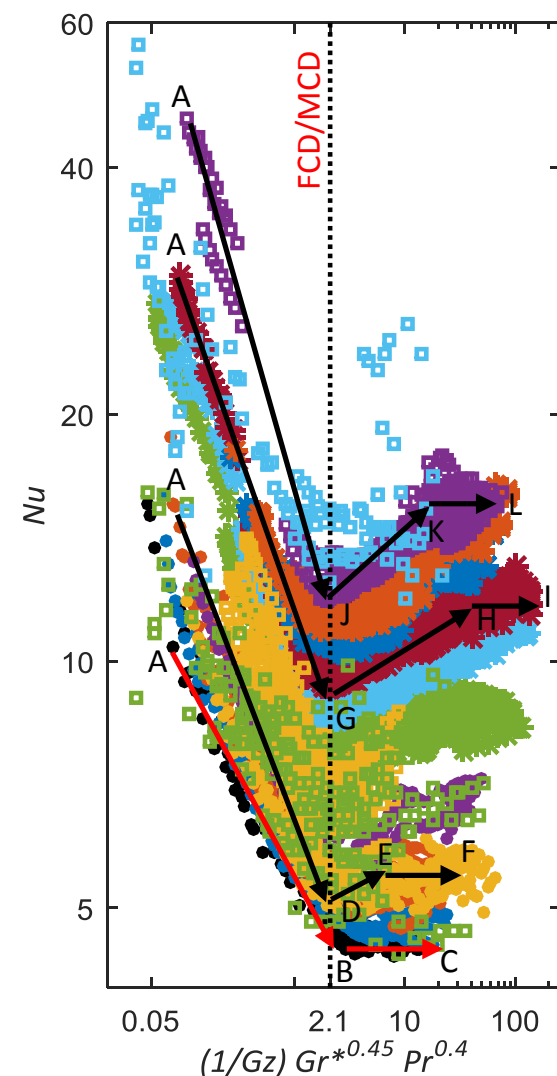

(b)

Fig. 9: Nusselt numbers as a function of (a) $(1 / G z) G^{0.57} \operatorname{Pr}^{0.4}$ and (b) $(1 / G z) G r^{0.45} \mathrm{Pr}^{0.4}$, to determine FCD/MCD boundary. The solid markers represent the results (at different heat fluxes) in the $4 \mathrm{~mm}$ test section, while the star and square markers represent the results in the $11.5 \mathrm{~mm}$ and literature $[41,44,59,60]$, respectively. The forced convection results are indicated by red arrows A-B-C. Arrows A-D-E-F and A-G-H-I indicate the trend at a heat flux of $3 \mathrm{~kW} / \mathrm{m}^{2}$ in the $4 \mathrm{~mm}$ and $11.5 \mathrm{~mm}$ test sections, while arrows A-J-K-L indicate the trend at a heat flux of $4 \mathrm{~kW} / \mathrm{m}^{2}$ in the $19 \mathrm{~mm}$ test section. 
Similarly for the modified Grashof number, it follows from Fig. 9(b) that the FCD/MCD boundary (points B, D, G and J in Fig. 9(b), corresponding to the same points in Fig. 5(a) and Fig. 6) can be estimated to be at $(1 / G z) G r^{* 0.45} \mathrm{Pr}^{0.4}=C_{2}$, where the constant $C_{2}$ is approximately equal to 2.1 . Using the boundary $(1 / G z) G r^{* 0.45} \mathrm{Pr}^{0.4}=C_{2}$, the length required for the flow to be in the MCD region was determined as:

$$
L t_{M C D}=\frac{C_{2} \operatorname{RePr} r^{0.6} D}{G r^{* 0.45}}=\frac{C_{2} L t_{F C}}{0.12 G r^{* 0.45} \operatorname{Pr}^{0.4}}
$$

\subsubsection{MCD/FD boundary}

From Fig. 5(a) it follows that the location at which the flow became fully developed (MCD/FD boundary) was not as distinct as the FCD/MCD boundary, since the gradient of the Nusselt numbers did not change from negative to positive, but gradually from positive to zero. It was concluded from Fig. 8 that the forced convection thermal entrance length equations became increasingly inaccurate when the Grashof numbers were increased. Experimental data for high Prandtl number fluids in the MCD region are rare, since the increased viscosity prevents free convection effects to dominate the entrance effects. This boundary was therefore developed mainly with water data, however a single case of $60 \%$ diethylene glycol data at a Reynolds number of approximately 1600 [60] was included, since free convection effects dominated the entrance effects in a small part of the test section. As the Prandtl numbers varied between 45.7 and 53, this case extended the Prandtl number range of this boundary.

To determine the MCD/FD boundary, the Nusselt numbers were plotted (Fig. 10(a)) in terms of $(1 / G z) G r^{0.4} \operatorname{Pr}^{1.65}(x / D)^{0.3}$, to account for mixed convection conditions $(G r)$ and different test fluids $(P r)$. It was found that the non-dimensional axial distance $(x / D)$ had to be included, since the thermal boundary layer thickness, and thus free convection effects, changed along the tube length when the flow was developing. From points $\mathrm{B}, \mathrm{E}, \mathrm{H}$ and $\mathrm{K}$ in Fig. 10(a) (corresponding to the same points in Fig. 5(a) and Fig. 6), it follows that the MCD/FD boundary was estimated to be at $(1 / G z) G r^{0.4} \operatorname{Pr}^{1.65}(x / D)^{0.3}=C_{3}$, where the constant $C_{3}$ is approximately equal to 130 .

Using the boundary $(1 / G z) G r^{0.4} \operatorname{Pr}^{1.65}(x / D)^{0.3}=C_{3}$, the length required for the flow to become fully developed during mixed convection conditions was determined as: 


$$
L t_{F D}=D\left(\frac{C_{3} R e}{G r^{0.4} P r^{0.65}}\right)^{10 / 13}=\frac{L t_{F C}}{0.12}\left(\frac{C_{3}}{R e^{0.3} \operatorname{Pr}^{1.95} G r^{0.4}}\right)^{10 / 13}
$$

From Eq. (24) it follows that the thermal entrance length is proportional to the Reynolds number and tube diameter, but inversely to the Grashof number and Prandtl number. This explains why fully developed flow (or very close to) was obtained in the experimental data set of Chen [60] although the maximum length-to-inside diameter ratio was only 400 and the Prandtl number high $(45<\operatorname{Pr}<53)$.

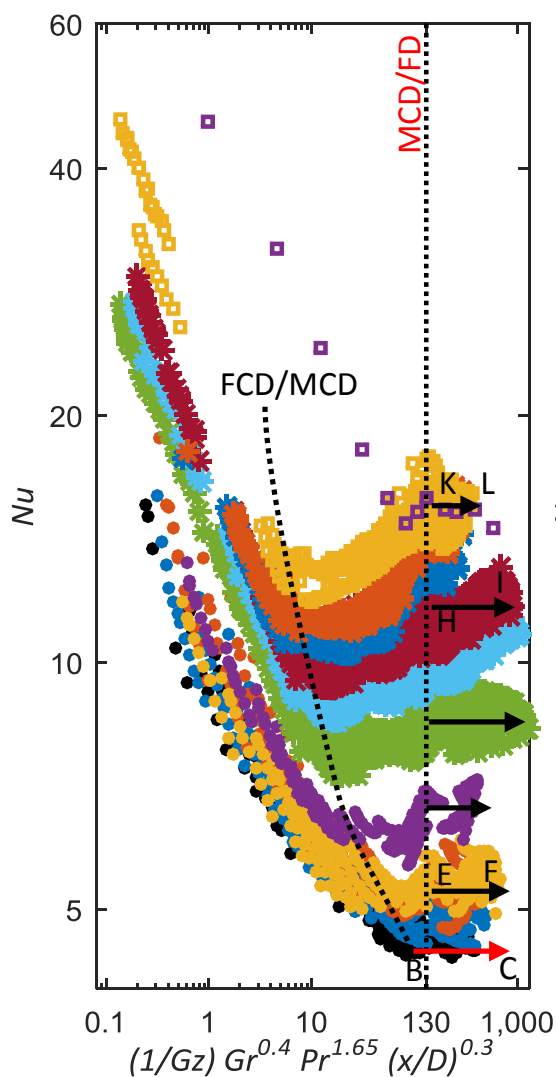

(a)

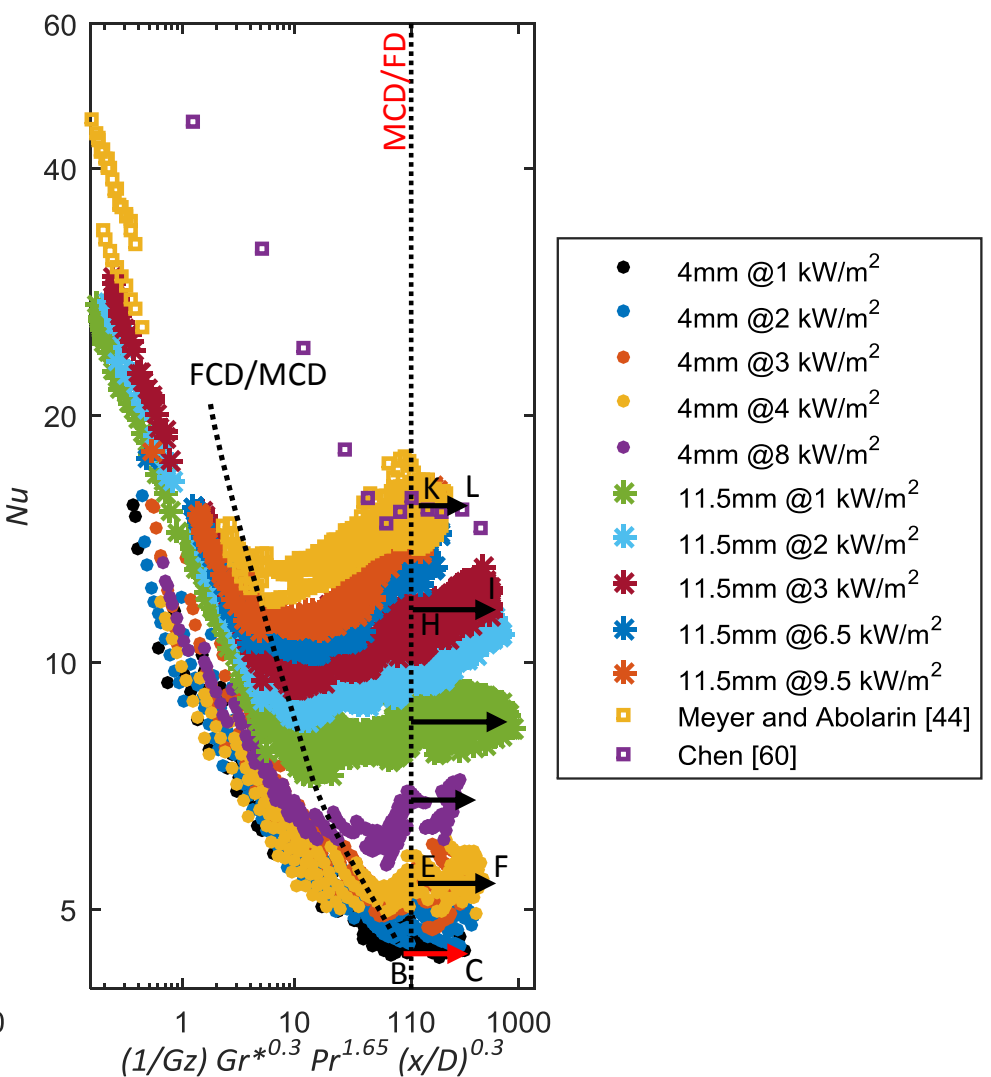

(b)

Fig. 10: Nusselt numbers as a function of (a) $(1 / G z) G r^{0.4} \operatorname{Pr}^{1.65}(x / D)^{0.3}$ and $(b)(1 / G z) G r^{* 0.3} \operatorname{Pr}^{1.65}(x / D)^{0.3}$ to determine MCD/FD boundary. The solid markers represent the results (at different heat fluxes) in the $4 \mathrm{~mm}$ test section, while the star and square markers represent the results in the $11.5 \mathrm{~mm}$ and literature [44, 60], respectively.

The same procedure was then repeated for the modified Grashof number. From points B, E, $\mathrm{H}$ and $\mathrm{K}$ in Fig. 10(b) (corresponding to the same points in Fig. 5(a) and Fig. 6), it followed that the MCD/FD boundary was estimated to be at $(1 / G z) G r^{* 0.3} \operatorname{Pr}^{1.65}(x / D)^{0.3}=C_{4}$, where the constant $C_{4}$ is approximately equal to 110 . The length required for the flow to become fully developed during mixed convection conditions, as a function of $G r^{*}$, was determined as: 


$$
L t_{F D}=D\left(\frac{C_{4} R e}{G r^{* 0.3} P r^{0.65}}\right)^{10 / 13}=\frac{L t_{F C}}{0.12}\left(\frac{C_{4}}{G r^{* 0.3} R e^{0.3} \operatorname{Pr}^{1.95}}\right)^{10 / 13}
$$

\subsubsection{Conditions for no MCD region}

Cheng and $\mathrm{Ou}$ [23] numerically investigated free convection effects in large Prandtl number fluids and found that when the Rayleigh number was greater than $3.75 \times 10^{5}$, the local Nusselt numbers decreased along the tube length and became constant. Similar results were also obtained in literature [22, 41, 60-62] when higher Prandtl number fluids, such as glycols and nanofluids, were used. Fig. 11 contains three cases of local Nusselt numbers as a function of axial position of experimental data from literature [60-62] using high Prandtl number fluids. From all three data sets it follows that the Nusselt numbers decreased near the inlet of the test section and then became constant, indicating that the flow was fully developed. As the Nusselt numbers did not increase with axial position before they became constant, the MCD region became negligible, and the local Nusselt numbers changed from the FCD region directly to the FD region. However, the fully developed Nusselt numbers were significantly higher than 4.36 (indicated by the horizontal black dotted line), confirming that mixed convection conditions existed, and it also increased with increasing Prandtl number.

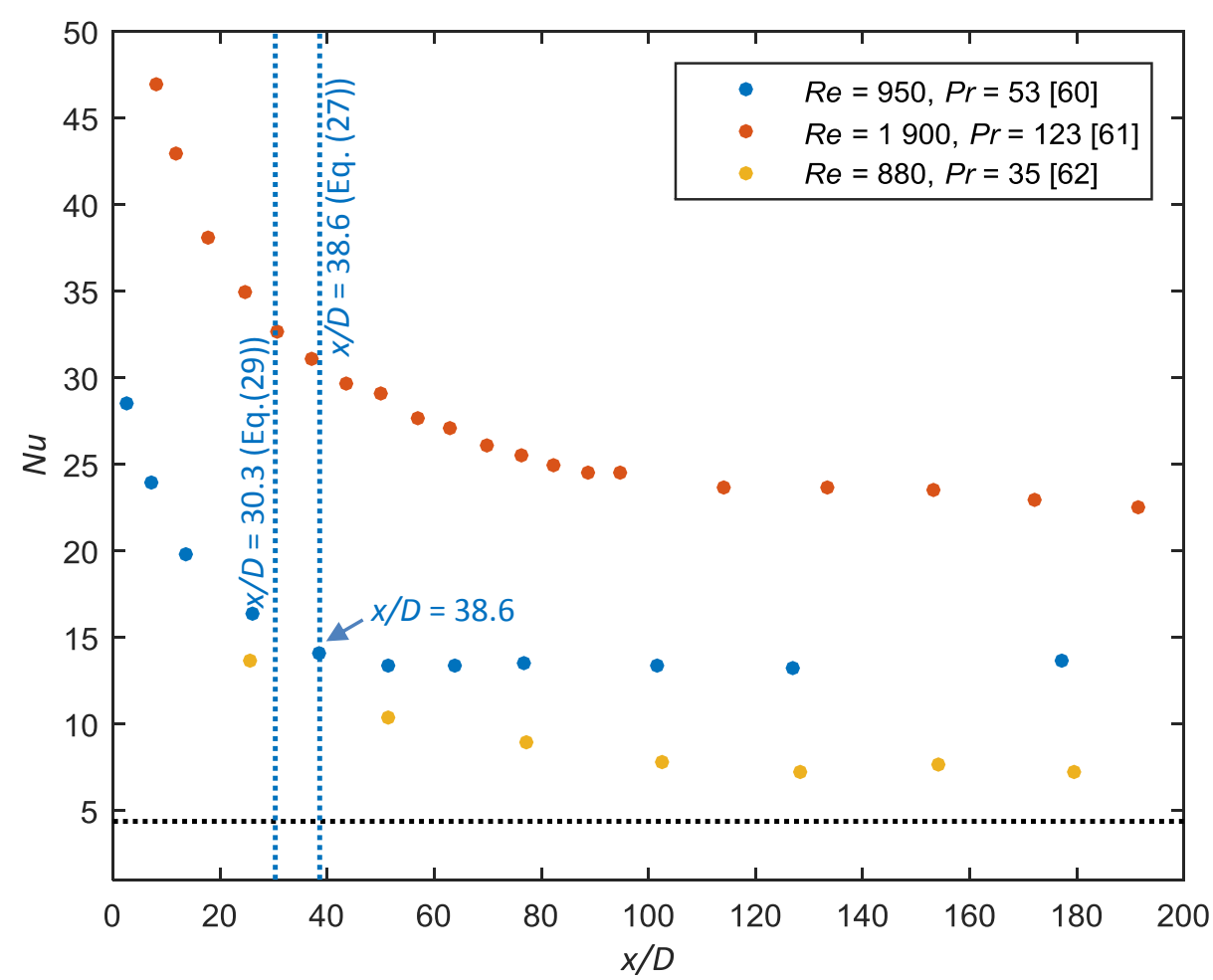

Fig. 11: Local Nusselt numbers as a function of axial position of experimental data from literature [60-62] using high Prandtl number fluids. 
Everts and Meyer [45] investigated the effect of the fluid properties of water and ethylene glycol on free convection effects. It was found that due to the significantly higher viscosity in the centre of the tube, free convection effects were restricted to the thermal boundary layer, and could not lead to secondary flow that assists in the diffusion of the heat from the surface to the centre of the tube.

The Grashof number, $G r_{F C D / F D}$, where the FCD/MCD and MCD/FD boundaries become equal, will represent the point where the MCD region is negligble. Thus at this condition, the flow will change from the FCD region to the FD region without any MCD region. This is schematically illustrated by the purple line in Fig. 12.

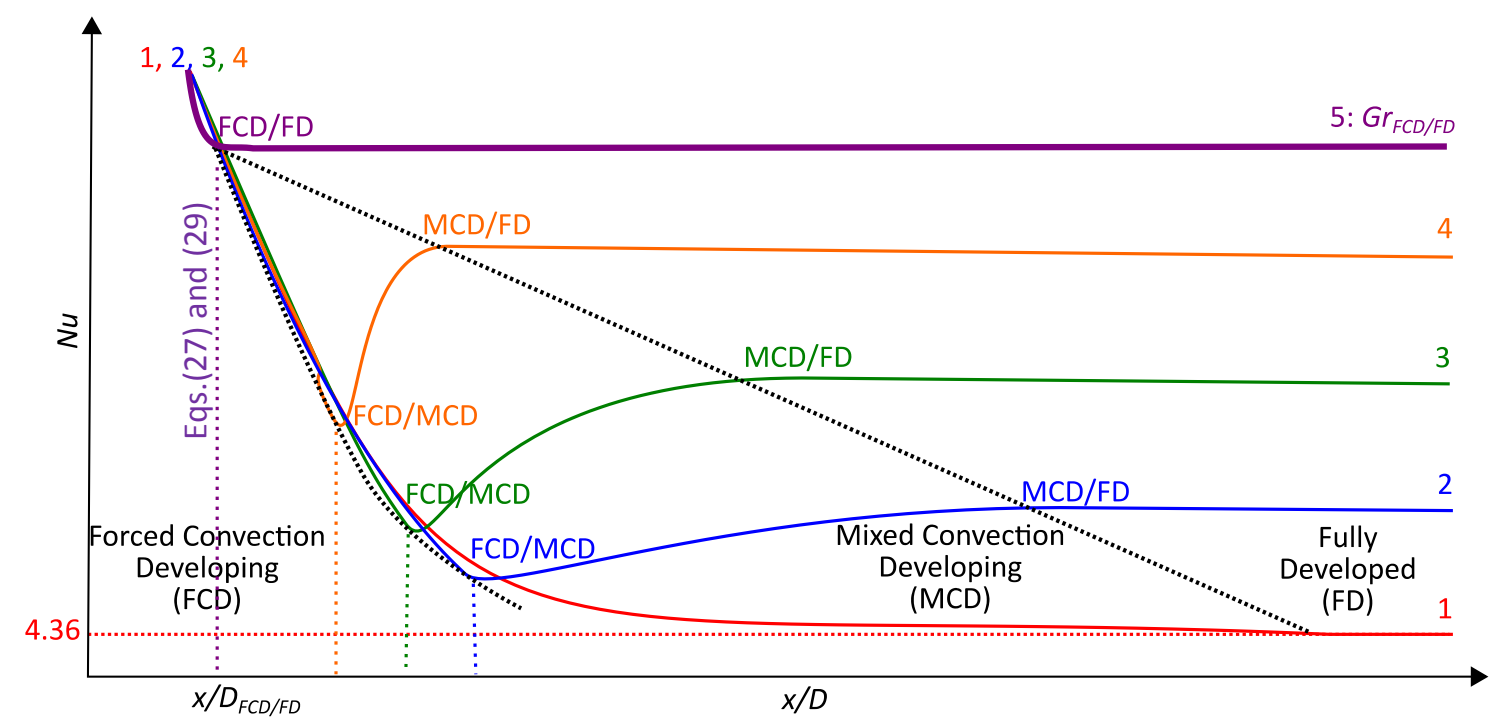

Fig. 12: Schematic representation of the effect of Grashof number on the local Nusselt numbers as a function of axial position, indicating the conditions of no MCD region.

For the MCD region to become negligble, Eqs. (22) and (24) were solved simultaneously as $L t_{M C D}=L t_{F D}$ :

$$
G r_{F C D / F D} \geq 1.78 \times 10^{-5} \operatorname{Re}^{0.88} \operatorname{Pr}^{4.19}
$$

Eq. (26) was then substituted into Eq. (22), to obtain the location where the FCD/MCD and MCD/FD boundaries become equal:

$$
\frac{x_{F C D / F D}}{D}=\frac{1223 R e^{0.5}}{\operatorname{Pr}^{1.79}}
$$

The same procedure was then repeated for the modified Grashof number, using Eqs. (23) and (25): 


$$
\begin{gathered}
G r_{F C D / F D}^{*} \geq 2.03 \times 10^{-6} \operatorname{Re}^{1.05} \operatorname{Pr}^{5.02} \\
\frac{x_{F C D / F D}}{D}=\frac{766 R e^{0.526}}{P r^{1.658}}
\end{gathered}
$$

From Eqs. (27) and (29) it follows the FCD/FD boundary is dependent on the ratio of the Reynolds number to the Prandtl number. Eqs. (26) to (29) were verified using the experimental data of Chen [60] (blue markers in Fig. 11). From this figure it follows that the Nusselt numbers became approximately constant at $x / D=38.6$, while Eqs. (27) and (29) predicted the FCD/FD boundary to be at $x / D=38.6$ and $x / D=30.3$ (within approximately $20 \%$ ), respectively.

As Eqs. (27) and (29) produced different results for Fig. 11, their sensitivity towards Prandtl number were evaluated for different cases of Reynolds number and Prandtl number, and the results are summarised in Table 4. From this table it follows that the deviation between the correlations at a Prandtl number of 3 was approximately $14 \%$. It then decreased to $3 \%$ when the Prandtl number was increased to 7 , but increased to $22 \%$ as the Prandtl number was increased to 50. This is as expected, since the majority of the data that was used to develop these correlations were at a Prandtl number of approximately 7. Less data has Prandtl numbers as low as 3, while only a single case of $60 \%$ diethylene glycol $(45.7<\operatorname{Pr}<53)$ data at a Reynolds number of approximately 1600 [60] was used to developed Eqs. (24) and (25). The Prandtl number in Table 4 was not increased further, since Eqs. (24) and (25) were limited to Prandtl numbers up to 53. The accuracy of Eqs. (27) and (29) for high and low Prandtl number fluids can be improved when more experimental data with high Prandtl numbers are available to modify Eqs. (24) and (25).

Table 4: Verification of FCD/FD boundary using Eqs. (27) and (29).

\begin{tabular}{lccc}
\hline & $x / D($ Eq. $(27))$ & $x / D($ Eq. $(29))$ & $\%$ difference \\
\hline$R e=500, P r=3$ & 3827 & 3257 & 16.1 \\
$R e=500, P r=7$ & 840 & 799 & 4.9 \\
$\operatorname{Re}=500, \operatorname{Pr}=50$ & 25 & 31 & 20.9 \\
$\operatorname{Re}=1000, P r=3$ & 5412 & 4690 & 14.3 \\
$\operatorname{Re}=1000, P r=7$ & 1188 & 1151 & 3.1 \\
$\operatorname{Re}=1000, P r=50$ & 35 & 44 & 22.7 \\
$\operatorname{Re}=2000, P r=3$ & 7654 & 6753 & 12.5 \\
$\operatorname{Re}=2000, P r=7$ & 1680 & 1657 & 1.3 \\
$\operatorname{Re}=2000, P r=50$ & 50 & 64 & 24.5 \\
\hline
\end{tabular}




\subsection{Local Nusselt number correlations}

To develop a correlation that accurately predicts the local Nusselt numbers in all three regions (Fig. 5(a)), three separate correlations were first developed for the FCD, MCD and FD regions. It was found that the heat transfer characteristics in the MCD and FD regions were similar, since both correlations were a function of the Grashof number (or modified Grashof number), Prandtl number and Graetz number. Therefore, a combined correlation for the MCD and the FD regions was developed. The method of Churchill and Usagi [64] was used to combine the equation for the FCD region $\left(N u_{1}\right)$ and the combined MCD and FD regions $\left(N u_{2}\right)$, and it was found that the results did not improve significantly for exponents larger than 6. Eqs. (30) and (31) can be used to calculate the local Nusselt numbers in terms of the Grashof number and modified Grashof number, and are thus valid for all three laminar regions:

$$
\begin{gathered}
N u=4.36+\left(N u_{1}^{6}+N u_{2}^{6}\right)^{1 / 6} \\
N u_{1}=\left(0.33 G z^{0.54}-0.84\right) P^{-0.2} \\
N u_{2}=\left(0.207 G r^{0.305}-1.19\right) P r^{0.5} G z^{-0.08} \\
N u=4.36+\left(N u_{1}^{6}+N u_{2}^{6}\right)^{1 / 6} \\
N u_{1}=\left(0.33 G z^{0.54}-0.84\right) P r^{-0.2} \\
N u_{2}=\left(0.202 G r^{* 0.254}-1.23\right) P r^{0.45} G z^{-0.06}
\end{gathered}
$$

Table 5 summarises the ranges and performance of the correlations compared to the experimental results of this study, using 5680 data points, and this study and literature [41, $53,59,60,62,65,66]$, using a total of 7675 data points. From this table it follows that both correlations predicted almost all the data $(99 \%)$ of this study within $20 \%$. Furthermore, approximately $80 \%$ of the experimental data of this study and literature $[41,44,59,60,62$, $65,66]$, were predicted within $10 \%$. 
Table 5: Overall performance and ranges of local laminar Nusselt number correlations. The value of $n$ represents the number of data points and Ave \%, the average deviation.

\begin{tabular}{|c|c|c|c|c|c|c|c|c|}
\hline \multirow{2}{*}{ Eq. } & \multicolumn{4}{|c|}{ This study only } & \multicolumn{4}{|c|}{$\begin{array}{l}\text { This study and literature } \\
{[41,44,59,60,62,65,66]}\end{array}$} \\
\hline & $n$ & $\begin{array}{c} \pm 10 \% \\
{[\%]}\end{array}$ & $\begin{array}{c} \pm 20 \% \\
{[\%]}\end{array}$ & Ave $\%$ & $n$ & $\begin{array}{c} \pm 10 \% \\
{[\%]}\end{array}$ & $\begin{array}{c} \pm 20 \% \\
{[\%]}\end{array}$ & Ave $\%$ \\
\hline Gr: (30) & 5680 & 87 & 99 & 5.4 & 7675 & 78 & 94 & 7.4 \\
\hline$G r^{*}:(31)$ & 5680 & 89 & 99 & 5.3 & 7675 & 78 & 94 & 7.3 \\
\hline Range & \multicolumn{4}{|c|}{$\begin{array}{c}467 \leq \operatorname{Re} \leq 3217 \\
3 \leq \operatorname{Pr} \leq 7.4 \\
2.6 \leq G z \leq 5589 \\
30 \leq G r \leq 2.49 \times 10^{5} \\
541 \leq G r^{*} \leq 4.01 \times 10^{6}\end{array}$} & \multicolumn{4}{|c|}{$\begin{array}{c}48 \leq \operatorname{Re} \leq 3217 \\
2.9 \leq \operatorname{Pr} \leq 282 \\
2.6 \leq G z \leq 1.14 \times 10^{5} \\
5.5 \leq G r \leq 4.51 \times 10^{5}, \\
41.3 \leq G r^{*} \leq 7.27 \times 10^{6}\end{array}$} \\
\hline
\end{tabular}

To determine the validity/accuracy of the correlations for Prandtl numbers less than one, the performance of the correlations was determined using experimental data conducted using air as the test fluid. Apart from the experimental data of McComas and Eckert [18], it was found that limited complete experimental data (Reynolds numbers, Nusselt numbers, Grashof numbers and axial position) conducted using air were available in literature. The performance of Eqs. (30) and (31) was determined using 34 experimental data points ( $\operatorname{Re} \approx 740, \operatorname{Pr} \approx 0.7,3.34<G r<491)$. It was found that Eq. (30) was able to predict $71 \%$ of the data within $20 \%$ and the average deviation was $15 \%$, while Eq. (31) was able to predict $80 \%$ of the data within $20 \%$ and the average deviation was $13 \%$.

\subsection{Average laminar Nusselt numbers}

Shah [25] developed a correlation to determine the average Nusselt numbers of developing flow, however, it was limited to constant fluid properties. The average mixed convection Nusselt number correlations that are available, are valid for a constant surface temperature boundary condition $[67,68]$, and not for a constant heat flux boundary condition. Therefore, the local Nusselt number correlations (FCD region $\left(N u_{1}\right)$ and combined MCD and FD regions $\left(N u_{2}\right)$ in Eqs. (30) and (31)) were combined and integrated along the tube length, $L$. The following correlation was obtained to calculate the average laminar Nusselt number over a length $L$, measured from the tube inlet: 


$$
\begin{gathered}
\overline{N u}=4.36+\overline{N u}_{1}+\overline{N u}_{2} \\
\overline{N u}_{1}=\frac{1}{L} \int_{0}^{L t_{M C D}} N u_{1} d L=\frac{1}{L}\left(-0.84 P r_{b}^{-0.2} L t_{M C D}+0.72\left(R e_{b} D\right)^{0.54} P r_{b}^{0.34} L t_{M C D}^{0.46}\right) \\
\overline{N u}_{2}=\frac{1}{L} \int_{L t_{M C D}}^{L} N u_{2} d L=\frac{1}{L}\left(0.207 G r_{b}^{0.305}-1.19\right) P r_{b}^{0.42}\left(R e_{b} D\right)^{-0.08}\left(L-L t_{M C D}\right) \\
L t_{M C D}=\frac{2.4 R e_{b} P r_{b}^{0.6} D}{G r_{b}^{0.57}} \text { for } L>L t_{M C D} \\
L t_{M C D}=L \text { for } L<L t_{M C D}
\end{gathered}
$$

In this equation, as well as Eqs. (33)-(35), $P r, R e$ and $G r$ were evaluated at the bulk fluid temperature. Similarly, Eq. (33) was developed to calculate the Nusselt numbers as a function of the modified Grashof number:

$$
\begin{gathered}
\overline{N u}=4.36+\overline{N u}_{1}+\overline{N u}_{2} \\
\overline{N u}_{1}=\frac{1}{L} \int_{0}^{L t_{M C D}} N u_{1} d L=\frac{1}{L}\left(-0.84 P r_{b}^{-0.2} L t_{M C D}+0.72\left(R e_{b} D\right)^{0.54} P r_{b}^{0.34} L t_{M C D}^{0.46}\right) \\
\overline{N u}_{2}=\frac{1}{L} \int_{L t_{M C D}}^{L} N u_{2} d L=\frac{1}{L}\left(0.202 G r_{b}^{* 0.254}-1.23\right) P r_{b}^{0.39}\left(R e_{b} D\right)^{-0.06}\left(L-L t_{M C D}\right) \\
L t_{M C D}=\frac{2.1 R e_{b} P r_{b}^{0.6} D}{G r_{b}^{* 0.45}} \text { for } L>L t_{M C D} \\
L t_{M C D}=L \text { for } L<L t_{M C D}
\end{gathered}
$$

Table 6: Overall performance and ranges of average laminar Nusselt number correlations. The value of $n$ represents the number of data points and Ave \%, the average deviation.

\begin{tabular}{ccccc}
\hline \multirow{2}{*}{ Eq. } & \multicolumn{4}{c}{ Experimental data from this study } \\
\cline { 2 - 5 } Gr: $(32)$ & 495 & $\pm 10 \%[\%]$ & $\pm 20 \%[\%]$ & Ave $\%$ \\
$G r^{*}:(33)$ & 495 & 98 & 100 & 3.6 \\
\hline \multirow{2}{*}{ Range } & $48 \leq R e \leq 3$ & 95 & 100 & 3.6 \\
\hline
\end{tabular}

Table 6 summarises the ranges and performance of Eqs. (32) and (33) using 495 experimental data points of this study. From this table it follows that both correlations performed very well and were able to predict $95 \%$ of the data within $10 \%$ and all the data within $20 \%$. 


\subsection{Average laminar friction factors}

By making use of the Colburn Analogy [63], the relationship between friction factor (pressure drop) and Colburn $j$-factor (heat transfer) was used by Everts and Meyer [46] to obtain a correlation to calculate the friction factors as a function of Nusselt number and Grashof number:

$$
\bar{f}=\frac{109.71 \overline{N u}}{R e_{b} P r_{b}^{1 / 3} G r_{b}^{0.215}}
$$

where $\overline{N u}$ can be calculated using Eq. (32). A correlation was also developed in terms of the modified Grashof number:

$$
\bar{f}=\frac{115.01 \overline{N u}}{\operatorname{Re}_{b} P r_{b}^{1 / 3} G r_{b}^{*} 0.179}
$$

where $\overline{N u}$ can be calculated using Eq. (33).

Table 7: Overall performance and ranges of average laminar friction factor correlations. The value of $n$ represents the number of data points and Ave \%, the average deviation.

\begin{tabular}{ccccc}
\hline \multirow{2}{*}{ Eq. } & $n$ & $\pm 10 \%[\%]$ & $\pm 20 \%[\%]$ & Ave $\%$ \\
\cline { 2 - 5 } & 495 & 100 & 100 & 2.4 \\
$G r:(32),(34)$ & 495 & 100 & 100 & 2.2 \\
$G r^{*}:(33),(35)$ & $467 \leq R e \leq 3$ & $217,3 \leq P r \leq 7.4,2.6 \leq G z \leq 5589,30 \leq G r \leq 2.49 \times 10^{5}$, \\
Range & \multicolumn{5}{c}{$541 \leq G r^{*} \leq 4.01 \times 10^{6}$} \\
\hline
\end{tabular}

The ranges and performance of Eqs. (34) and (35) are summarised in Table 7. From this table it follows that both friction factor correlations were able to predict all the experimental data within $10 \%$, with an average deviation of $2.2-2.4 \%$.

\section{Results: Quasi-turbulent and turbulent flow}

Very limited results in the quasi-turbulent and turbulent flow regimes are presented in this paper, as it is only required to link the results given in Fig. 6 and Fig. 13, to Fig. 16. Fig. 13 compares the Nusselt numbers as a function of axial position for Reynolds numbers between 4000 and 8000 at heat fluxes of $3 \mathrm{~kW} / \mathrm{m}^{2}$ and $8 \mathrm{~kW} / \mathrm{m}^{2}$ in the $4 \mathrm{~mm}$ test section, and at heat fluxes of $1 \mathrm{~kW} / \mathrm{m}^{2}$ and $3 \mathrm{~kW} / \mathrm{m}^{2}$ in the $11.5 \mathrm{~mm}$ test section. 


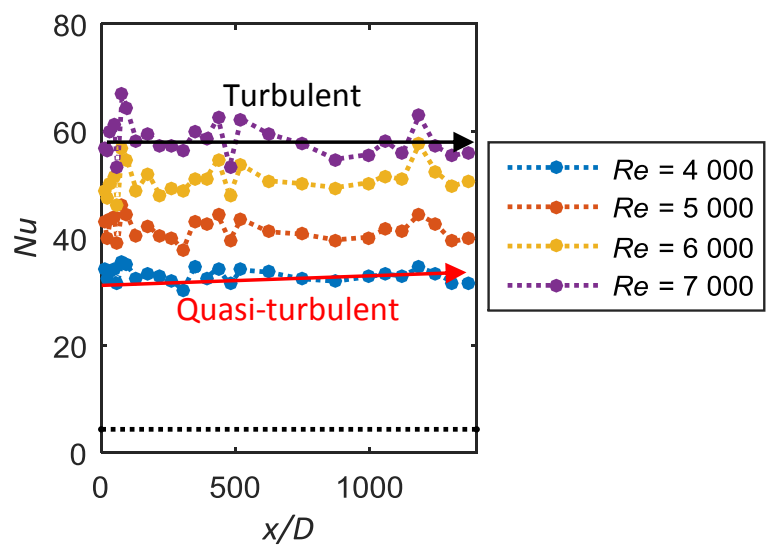

(a)

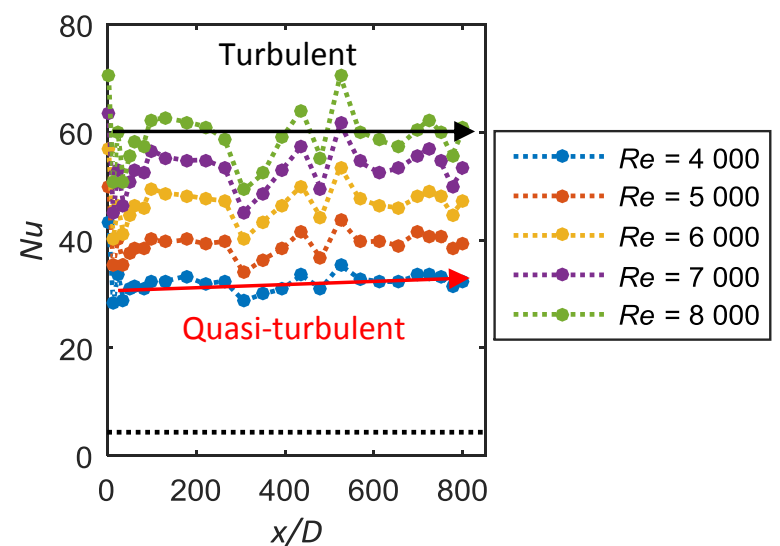

(c)

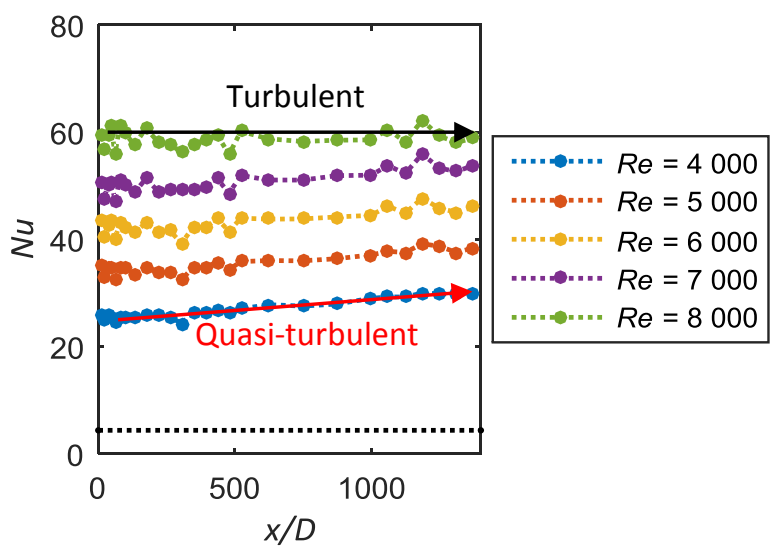

(b)

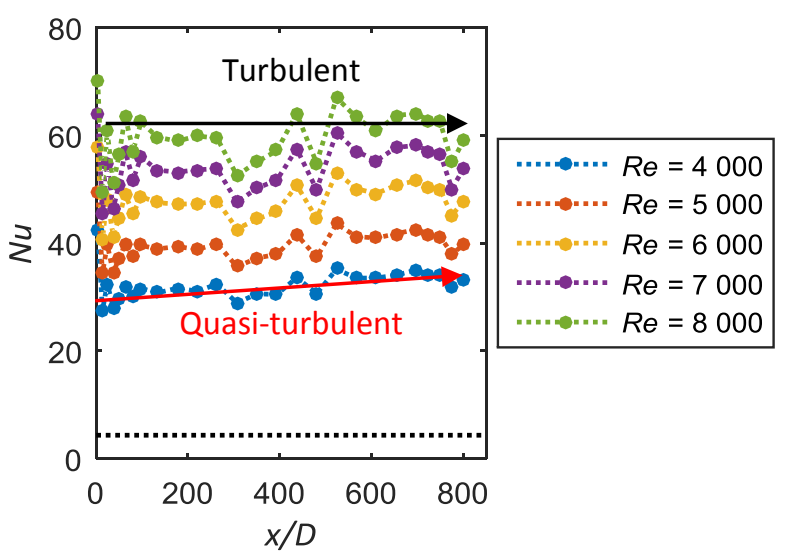

(d)

Fig. 13: Comparison of Nusselt numbers as a function of axial position for Reynolds numbers between 4000 and 8000 at a heat flux of (a) $3 \mathrm{~kW} / \mathrm{m}^{2}$ and (b) $8 \mathrm{~kW} / \mathrm{m}^{2}$ in the $4 \mathrm{~mm}$ test section and at a heat flux of (c) $1 \mathrm{~kW} / \mathrm{m}^{2}$ and (d) $3 \mathrm{~kW} / \mathrm{m}^{2}$ in the $11.5 \mathrm{~mm}$ test section. The red and black arrows indicate the trends in the quasi-turbulent and turbulent flow regimes, respectively.

The thermal entrance length for turbulent flow (normally taken as approximately $10 \mathrm{D}$ [63]) can be regarded as negligible, since the Nusselt numbers remained constant along the entire tube length. Furthermore, the magnitude of the Nusselt numbers increased with increasing Reynolds numbers due to the enhanced mixing inside the test section. As expected, at a specific Reynolds number, for example 8000 , there was no significant difference between the magnitude of the Nusselt numbers in the different test sections and at different heat fluxes, confirming that free convection effects were negligible. However, from Fig. 13(b) (this figure is selected as it is easy to distinguish) it follows that at Reynolds numbers between 4000 and 7000 , the Nusselt numbers increased slightly along the tube length. This increase became lower as the Reynolds number was increased and at a Reynolds number of 8000 , the Nusselt numbers were constant along the entire tube length. Therefore, the flow was not yet fully turbulent (at $4000<R e<7000$ ), but still in the quasi-turbulent regime, which is the upper part of the transitional flow regime. In this flow regime, the flow 
approaches turbulent flow and the heat transfer characteristics are very similar to turbulent flow. However, as the flow is not fully turbulent yet, turbulent heat transfer corrections will slightly overpredict the Nusselt numbers in this region [58].

\section{Results: Transitional flow}

\subsection{Critical Reynolds number}

The critical Reynolds number corresponds to the Reynolds number before fluctuations in mass flow rate and temperature occur, and was obtained using the nomenclature defined by Everts and Meyer [45]. Fig. 14 contains the local Nusselt numbers as a function of axial position at the critical Reynolds number at different heat fluxes in the $4 \mathrm{~mm}$ and $11.5 \mathrm{~mm}$ test sections. The results in this graph are directly aligned to Fig. 5(b).

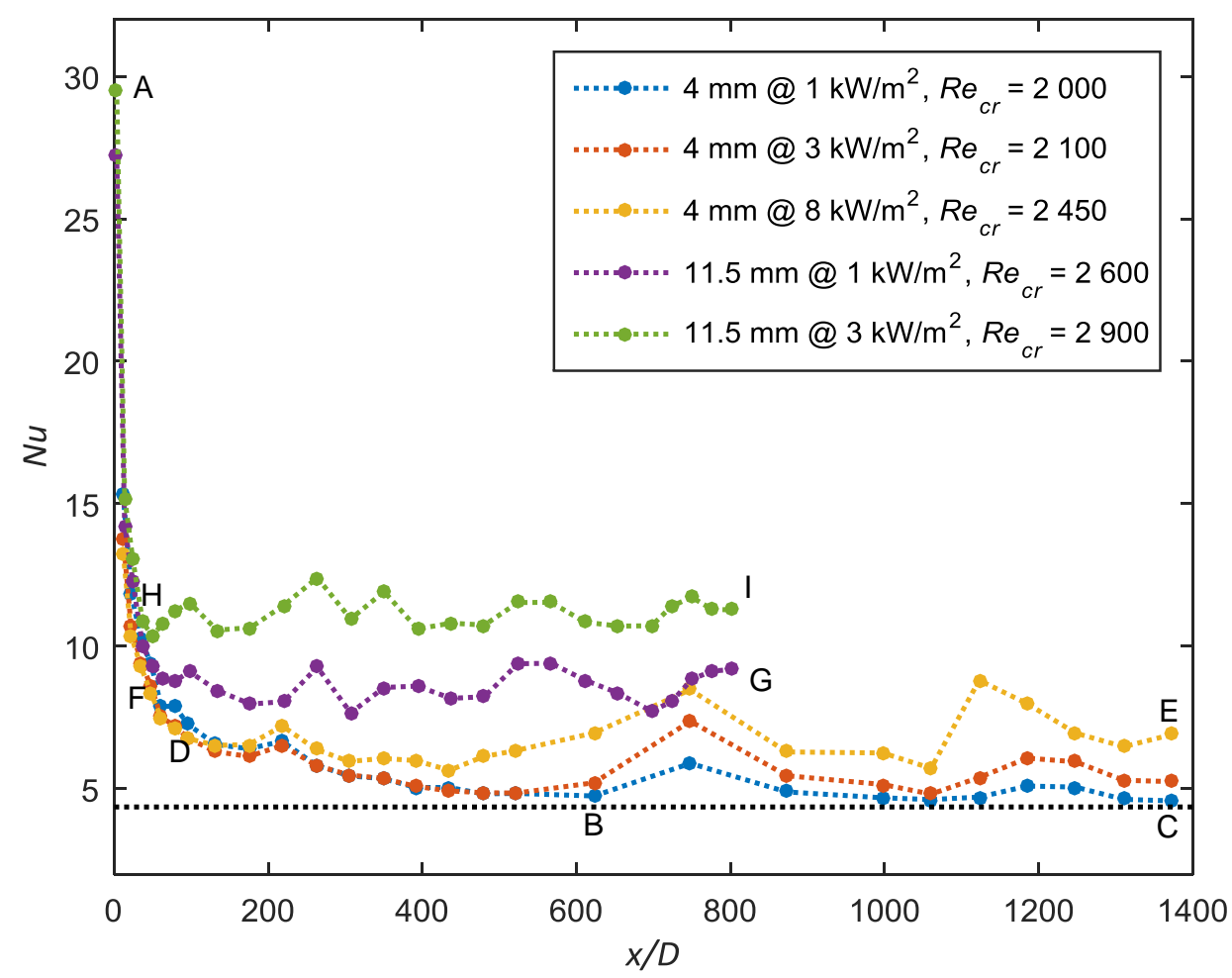

Fig. 14: Local Nusselt numbers as a function of axial position at the critical Reynolds number at different heat fluxes in the $4 \mathrm{~mm}$ and $11.5 \mathrm{~mm}$ test sections.

As the start of the transitional flow regime is affected by free convection effects [45], different critical Reynolds numbers were obtained for the different heat fluxes and tube diameters. From this figure it follows that, at the critical Reynolds number, the local Nusselt numbers decreased along the tube length and then became constant. As schematically illustrated in Fig. 5(b), it follows from points B, D, F and H in Fig. 14, that the axial position at which the Nusselt numbers became constant, decreased with increasing heat flux and tube diameter (thus increasing free convection effects). Furthermore, the magnitude of the fully 
developed Nusselt numbers increased with increasing Grashof number (points C, E, G, I in Fig. 5(b) and Fig. 14).

\subsection{Forced convection laminar-turbulent transition}

The results in this section are directly aligned to Fig. 5(c). Fig. 15 compares the local Nusselt numbers as a function of axial position for different Reynolds numbers in the transitional flow regime at a heat flux of $1 \mathrm{~kW} / \mathrm{m}^{2}$ in the $4 \mathrm{~mm}$ test section, therefore the flow was dominated by forced convection conditions. For comparison purposes, the theoretical Nusselt number of 4.36, for fully developed laminar forced convection flow, is indicated by the black dotted line. From this figure it follows that for Reynolds numbers between 2000 and 2 200, the trend of the local Nusselt numbers was similar to the critical Reynolds number (Fig. 5(b)). However, the location at which the Nusselt numbers became constant, decreased with increasing Reynolds number (points B and D in Fig. 15 and Fig. 5(c)). Furthermore, as schematically illustrated in Fig. 5(c), it follows from points $\mathrm{C}$ and $\mathrm{E}$ that the fluctuations inside the test section and increased fluid velocity led to enhanced mixing, therefore the magnitude of the Nusselt numbers increased.

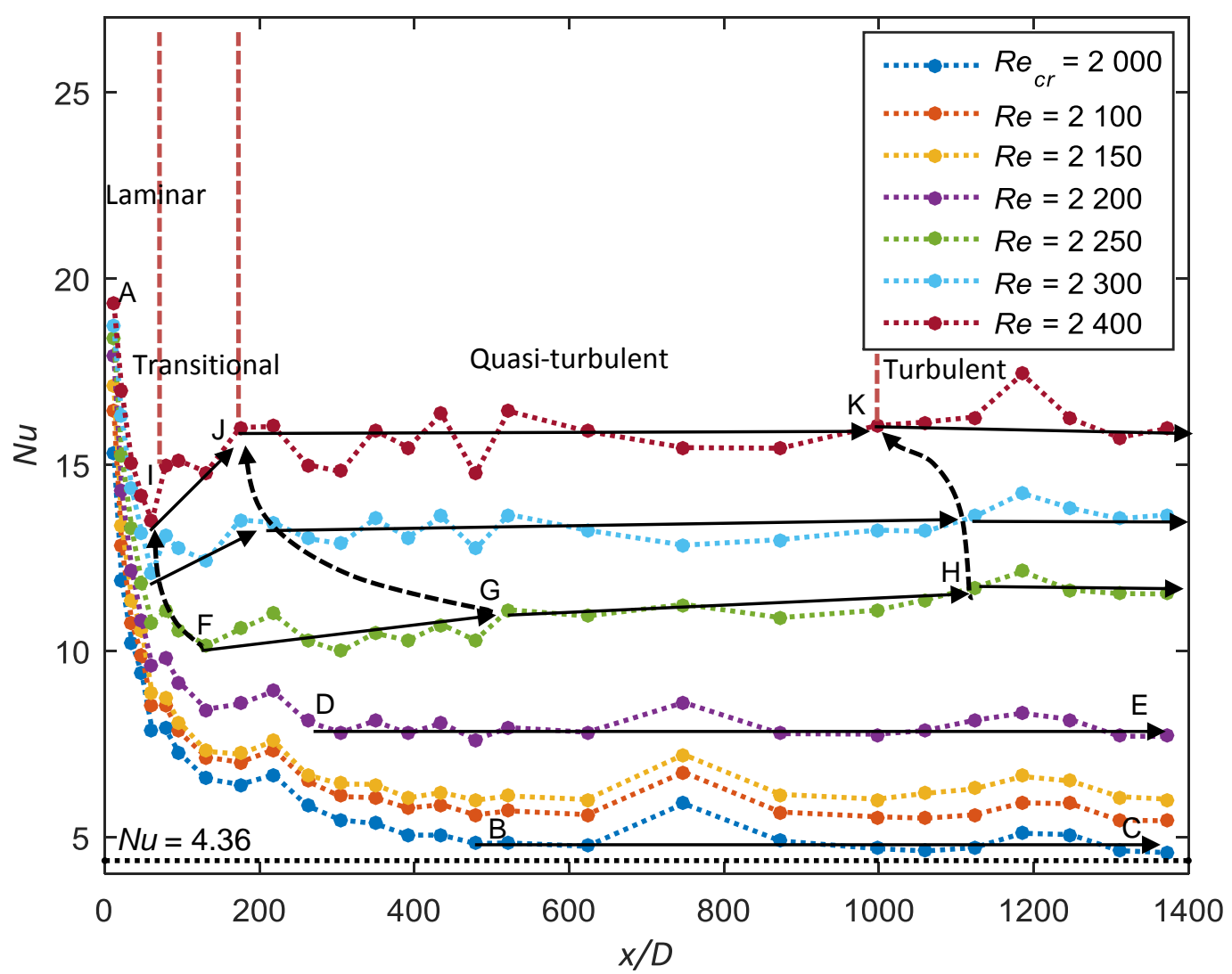

Fig. 15: Local Nusselt numbers as a function of axial position for Reynolds numbers between 2000 and 2400 at a heat flux of $1 \mathrm{~kW} / \mathrm{m}^{2}$ in the $4 \mathrm{~mm}$ test section. 
At Reynolds numbers greater than 2 200, the local Nusselt numbers decreased (laminar) near the inlet of the test section, then increased significantly (transition) with axial position, forming a 'dip'. It then increased slightly (quasi-turbulent) before it became constant (turbulent). As shown schematically by the green and yellow lines in Fig. 5(c), four different regions can be distinguished, and the different regions are indicated by the dotted red lines in Fig. 15, for a Reynolds number of 2400 . Due to the small heat flux that was applied (to ensure forced convection conditions), the temperature and Nusselt number uncertainties increased, which made it challenging to distinguish between the quasi-turbulent and turbulent flow regions.

The velocity profile was similar to laminar flow when the flow entered the test section. However, due to the higher fluid velocity the flow did not remain laminar, but passed through a transition and quasi-turbulent region before it became turbulent. From lines A-F and A-I it follows that the gradient of the Nusselt number lines in the laminar region decreased with increasing Reynolds number, since the thermal entrance length increased.

In the transition region, it was found that as the Reynolds number was increased, the depth and width of the dip decreased, and the trough of the dip (points F and I) occurred earlier. This caused the gradient of the Nusselt number lines in the transition region to increase with increasing Reynolds number (lines F-G and I-J), which implies that the transition from the laminar to the quasi-turbulent regions, occurred faster.

Similar to Fig. 13, the magnitude of the Nusselt numbers in the quasi-turbulent and turbulent regions increased as the Reynolds number was increased, due to the enhanced mixing inside the test section (points $\mathrm{H}$ and $\mathrm{K}$ ). Furthermore, the gradient of the Nusselt number lines in the quasi-turbulent region decreased with increasing Reynolds number, since the flow approached the turbulent flow regime where the Nusselt numbers remained constant. As schematically illustrated in Fig. 5(c), it seems that the location at which the Nusselt numbers became constant (points $\mathrm{H}$ and $\mathrm{K}$ in Fig. 14), decreased with increasing Reynolds number. This confirms that the transition from laminar to turbulent occurred faster with increasing Reynolds number.

It can thus be concluded that the transitional flow regime, in terms of fluid velocity (Reynolds number), between the laminar and turbulent flow regimes, was caused by the local transition region, in terms of axial position. This transition region occurred when the inlet velocity was high enough for mass flow rate and temperature fluctuations to occur, which caused the velocity profile of the fluid to change from laminar to turbulent along the tube length. 


\subsection{Mixed convection laminar-turbulent transition}

The results in this section are directly aligned to Fig. 5(d). Fig. 16 compares the Nusselt numbers as a function of axial position for transitional Reynolds numbers at heat fluxes of $1 \mathrm{~kW} / \mathrm{m}^{2}$ and $3 \mathrm{~kW} / \mathrm{m}^{2}$ in the $4 \mathrm{~mm}$ and $11.5 \mathrm{~mm}$ test sections. The results in Fig. 16(a) are for forced convection conditions, while the results in Fig. 16(b) to (d) are for mixed convection conditions. As the start and end of the transitional flow regime is affected by free convection effects [45], different Reynolds number ranges were used for the different heat fluxes and tube diameters. In each graph, the dark blue data represents the results at the critical Reynolds number, while the other colours represent the results at Reynolds number increments of 100. For comparison purposes, the theoretical Nusselt number of 4.36, for fully developed laminar forced convection flow, is indicated by the black dotted line.

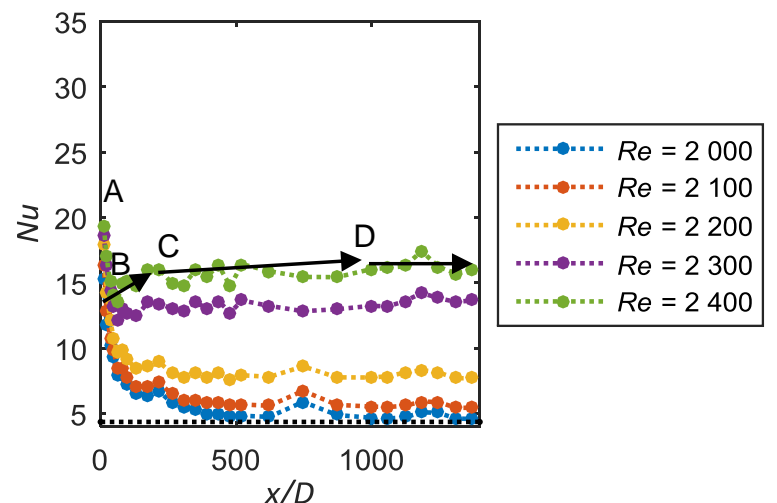

(a)

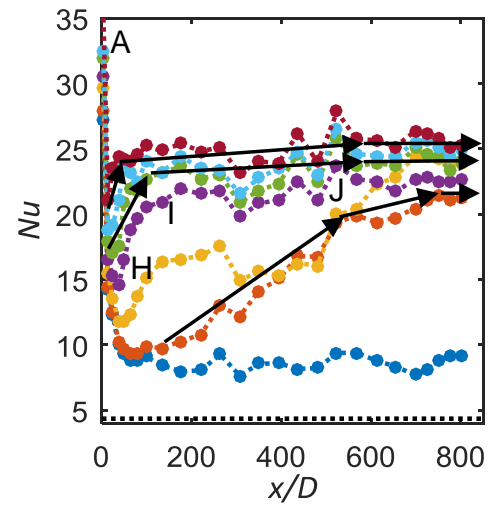

(c)

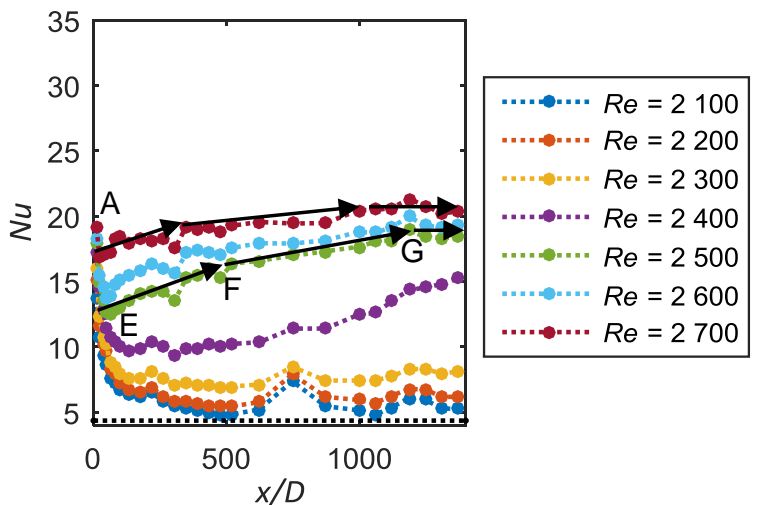

(b)

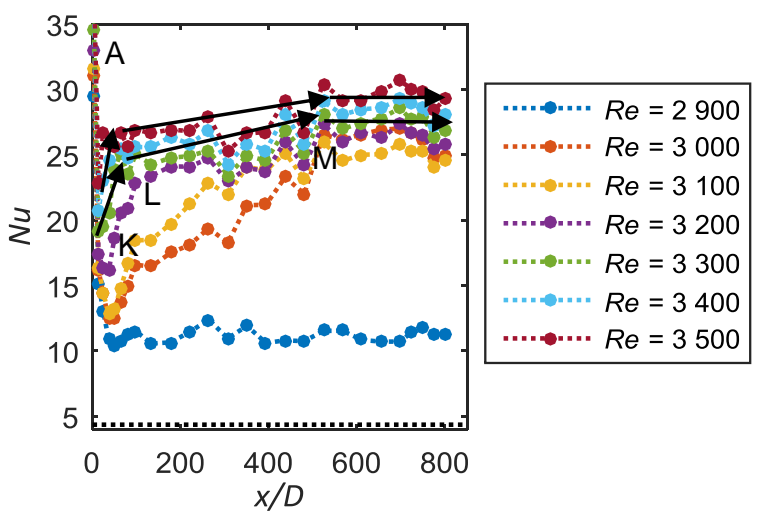

(d)

Fig. 16: Comparison of Nusselt numbers as a function of axial position for transitional Reynolds numbers at a heat flux of (a) $1 \mathrm{~kW} / \mathrm{m}^{2}$ (forced convection) and (b) $3 \mathrm{~kW} / \mathrm{m}^{2}$ in the $4 \mathrm{~mm}$ test section, and at a heat flux of (c) $1 \mathrm{~kW} / \mathrm{m}^{2}$ and (d) $3 \mathrm{~kW} / \mathrm{m}^{2}$ in the $11.5 \mathrm{~mm}$ test section. The dark blue data points represent the results at the critical Reynolds number, while the other colours represent the results at Reynolds number increments of 100.

For clarification, the results indicated by the green markers (at a Reynolds number of $\left.R e_{c r}+400\right)$ in Fig. 16(a) to (d), are summarised in Fig. 17. From points E, H and K it follows that the axial position at which the Nusselt numbers started to increase, decreased with 
increasing free convection effects. Furthermore, from arrows E-F, H-I and K-L it follows that the gradient of the Nusselt number lines in the transition region increased with increasing heat flux and tube diameter, thus increasing Grashof number in Fig. 5(d). Although free convection effects caused the flow to transition faster from the laminar to the quasi-turbulent region (points F, I and L), a significant tube length was still required for the flow to transition to fully turbulent flow. From arrows F-G, I-J and L-M it follows that the gradient of the Nusselt number lines in the quasi-turbulent region decreased with increasing free convection effects. In the turbulent region (points $\mathrm{G}, \mathrm{J}$ and $\mathrm{M}$ ), the magnitude of the Nusselt numbers increased with increasing heat flux and tube diameter, however the Nusselt numbers remained constant along the tube length, since the free convection effects were constant.

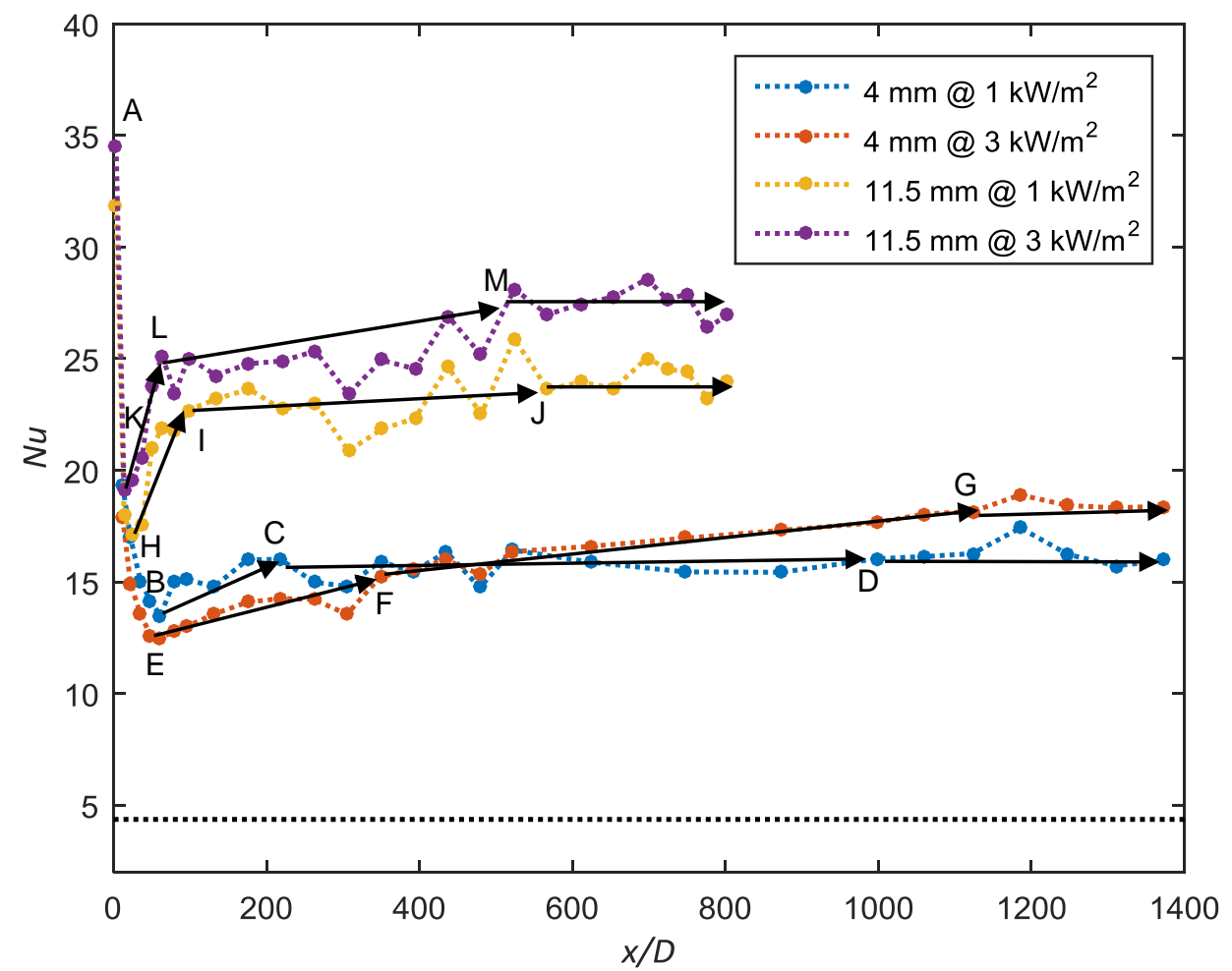

Fig. 17: Local Nusselt numbers as a function of axial position at a Reynolds number of $R e_{c r}+400$ at heat fluxes of $1 \mathrm{~kW} / \mathrm{m}^{2}$ and $3 \mathrm{~kW} / \mathrm{m}^{2}$ in the $4 \mathrm{~mm}$ and $11.5 \mathrm{~mm}$ test sections.

Although it follows from the results in Fig. 17 that free convection effects caused the laminar-turbulent transition to occur faster, free convection effects initially caused the flow to transition slower compared to forced convection conditions (points $\mathrm{C}$ and F). The same was true for the transition from the quasi-turbulent to turbulent regions (points $\mathrm{D}, \mathrm{G}, \mathrm{J}$ and $\mathrm{M}$ ). It can therefore be concluded that once free convection effects became significant, it first disturbed the fluctuations inside the test section and caused transition to occur slower. However, as free convection effects were increased (by increasing the tube diameter and heat 
flux) the fluctuations inside the test section were enhanced [45], which caused the flow to transition faster from laminar to turbulent.

\section{Recommendation for future work}

The boundaries and heat transfer characteristics of the three different laminar regions in Fig. 5(a) were quantified in this paper. However, the boundaries and heat transfer characteristics in the four different regions in the transitional flow regime (Fig. 5(c) and (d)), when the Reynolds number exceeded the critical Reynolds number, were not quantified. The reason being is that it was concluded in Sections 11.2 and 11.3 that the laminar-turbulent transition along the tube length is significantly affected by fluid velocity as well as free convection effects, and occurred faster with both increasing Reynolds number and Grashof number. It is recommended that this should be further investigated, to develop correlations to determine the boundaries of the different regions in the transitional flow regime, as well as to predict the local Nusselt numbers as a function of axial position.

\section{Conclusions}

The purpose of this study was to experimentally investigate the effects of free convection on the development of the local heat transfer characteristics in smooth horizontal circular tubes, heated with a constant heat flux. Two smooth circular test sections with inner diameters of $4 \mathrm{~mm}$ and $11.5 \mathrm{~mm}$ were used, and the maximum length-to-diameter ratios were 1373 and 872, respectively. Heat transfer measurements were taken at Reynolds numbers between 500 and 10000 at different heat fluxes. A total of 1046 mass flow rate measurements and 89459 temperature measurements were taken. Water was used as the test fluid and the Prandtl number ranged between 3 and 7. Although it was found that it was very challenging to experimentally obtain forced convection conditions, fully developed laminar forced convection conditions were successfully obtained by applying a very small heat flux.

It was found that a longer thermal entrance length was required when the flow is simultaneously hydrodynamically and thermally developing, as in this study, than when the flow is hydrodynamically fully developed and thermally developing. A coefficient of at least 0.12 (and not 0.05 as suggested in most literature) was therefore suggested for simultaneously hydrodynamically and thermally developing forced convection laminar flow. As the heat flux and tube diameter were increased, free convection effects became significant, which not only led to increased Nusselt numbers, but also a decreased thermal entrance length. 
Correlations were developed to calculate the thermal entrance length for mixed convection conditions.

Three different regions (FCD, MCD and FD) were identified in the local laminar heat transfer results and nomenclature and correlations were developed to define and quantify the boundaries of these regions. Correlations were also developed to calculate the local and average laminar Nusselt numbers of mixed convection developing flow.

The laminar-turbulent transition along the tube length occurred faster with increasing Reynolds number, due to the increased velocity of the fluid. However, this transition was also influenced by free convection effects. Free convection effects initially disturbed the fluctuations inside the test section, causing a slower laminar-turbulent transition compared to forced convection conditions. However, as the free convection effects were increased further, the fluctuations inside the test section were enhanced. The enhanced mixing caused the laminar-turbulent transition along the tube length to occur faster and the magnitude of the Nusselt numbers to increase.

\section{Acknowledgements}

The funding obtained in South Africa from the NRF, Stellenbosch University/ University of Pretoria Solar Hub, CSIR, EEDSM Hub, RDP and NAC is acknowledged and duly appreciated. The authors would also like to thank Professor K.C. Bell from Oklahoma State University and Professor C.C. Tang from the University of North Dakota, for making their laminar experimental data available $[60,62]$. The authors would also like to thank Professor A.J. Ghajar from Oklahoma State University for his fruitful discussion at the HEFAT2016 conference in Malaga, Spain. This work was produced as part of a $\mathrm{PhD}$ in mechanical engineering at the University of Pretoria by the second author under the supervision of the first author.

\section{References}

[1] W. Aung, Mixed Convection in Internal Flow, in: S. Kakaç, R.K. Shah, W. Aung (Eds.) Handbook of Single-Phase Convective Heat Transfer, John Wiley \& Sons, New York, 1987, pp. 15.11-15.51.

[2] G.D. Raithby, K.G.T. Hollands, Natural Convection, in: W.M. Rohsenow, J.P. Hartnett, Y.I. Cho (Eds.) Handbook of Heat Transfer, McGraw-Hill, Boston, 1998, pp. 4.1-4.99.

[3] J.D. Jackson, M.A. Cotton, B.P. Axcell, Studies of mixed convection in vertical tubes, Int. J. Heat Fluid Flow, 10(1) (1989) 1-15.

[4] J. Orfi, N. Galanis, C.T. Nguyen, Laminar fully developed incompressible flow with mixed convection in inclined tubes, International Journal of Numerical Methods for Heat \& Fluid Flow, 3(4) (1993) 341-355. 
[5] T. Maré, N. Galanis, S. Prétot, J. Miriel, Mixed convection with flow reversal in the entrance region of inclined tubes, International Journal of Numerical Methods for Heat \& Fluid Flow, 15(7) (2005) 740-756.

[6] Y. Mori, K. Futagami, S. Tokuda, M. Nakamura, Forced convective heat transfer in uniformly heated horizontal tubes, (1st report) Experimental study on the effect of buoyancy, Int. J. Heat Mass Transf., 9 (1966) 453-463.

[7] H.A. Mohammed, Y.K. Salman, The effects of different entrance sections lengths and heating on free and forced convective heat transfer inside a horizontal circular tube, International Communications in Heat and Mass Transfer, 37 (2007) 769-784.

[8] Y.A. Cengel, A.J. Ghajar, Heat and Mass Transfer: Fundamentals and Applications, 5th ed., McGraw-Hill, 2015.

[9] A. Faghri, Y. Zhang, J.R. Howell, Advanced Heat and Mass Transfer, Global Digital Press, Columbia, 2010.

[10] J.C. Han, Analytical Heat Transfer, CRC Press, Boca Raton, 2016.

[11] R.K. Shah, A.L. London, Laminar Flow Forced Convection in Ducts, Academic Press, New York, 1978.

[12] P.S. Ghoshdastidar, Heat Transfer, 2nd ed., Oxford University Press, New Delhi, 2012.

[13] R. Siegel, E.M. Sparrow, T.M. Hallman, Steady laminar heat transfer in a circular tube with a prescribed wall heat flux, Applied Scientific Research, 7 (1958).

[14] M.A. Ebadian, Z.F. Dong, Forced Convection, Internal Flow in Ducts, in: W.M. Rohsenow, J.P. Hartnett, Y.I. Cho (Eds.) Handbook of Heat Transfer, McGraw-Hill, Boston, 1998, pp. 5.1-5.137.

[15] J.H.I. Lienhard, J.H.V. Lienhard, A Heat Transfer Textbook, 3rd ed., Phlogiston Press, Cambridge, 2008.

[16] F. Durst, S. Ray, B. Ünsal, O.A. Bayoumi, The development lengths of laminar pipe and channel flows, J Fluids Eng Trans ASME, 127(6) (2005) 1154-1160.

[17] T.M. Hallman, Combined free and forced convection in a circular tube, $\mathrm{PhD}$ thesis, Purdue University, Lafayette, 1958.

[18] S. McComas, E. Eckert, Combined free and forced convection in a horizontal circular tube, Journal of Heat Transfer, 88(2) (1966) 147-152.

[19] R.L. Shannon, Combined free and forced laminar convection in a horizontal tube with a uniform heat flux, Journal of Heat Transfer, 90(3) (1968) 353-357.

[20] A.E. Bergles, R.R. Simonds, Combined forced and free convection for laminar flow in horizontal tubes with uniform heat flux, Int. J. Heat Mass Transf., 14(12) (1971) 1989-2000.

[21] B.S. Petukhov, A.F. Polyakov, Experimental investigation of viscogravitational fluid flow in a horizontal tube, Teplofiz. Vysok. Temp, 5 (1967) 87-95.

[22] S.W. Hong, S.M. Morcos, A.E. Bergles, Analytical and experimental results for combined forced and free laminar convection in horizontal tubes, in: 5th International Heat Transfer Conference, Tokyo, 1974.

[23] K.C. Cheng, J.W. Ou, Free convection effects on Graetz problem for large Prandtl number fluids in horizontal tubes with a uniform wall heat flux, in: 5th International Heat Transfer Conference, Tokyo, 1974, pp. 159-163.

[24] G.S. Barozzi, E. Zanchini, M. Mariotti, Experimental investigation of combined forced and free convection in horizontal and inclined tubes, Meccanica, 20 (1985) 18-27.

[25] R.K. Shah, Thermal entry length solutions for the circular tube amd parallel plates, in: 3rd National Heat and Mass Transfer Conference, India Institute of Technology, Bombay, 1975, pp. 1-12.

[26] M. Nishi, B. Ünsal, F. Durst, G. Biswas, Laminar-to-turbulent transition of pipe flows through puffs and slugs, Journal of Fluid Mechanics, 614 (2008) 425-446. 
[27] A.J. Ghajar, L.M. Tam, Laminar-transition-turbulent forced and mixed convective heat transfer correlations for pipe flows with different inlet configurations, in: Winter Annual Meeting of the American Society of Mechanical Engineers, Publ by ASME, New York, United States, 1991, pp. 15-23.

[28] A.J. Ghajar, K.F. Madon, Pressure drop measurements in the transition region for a circular tube with three different inlet configurations, Exp. Therm. Fluid Sci., 5(1) (1992) 129-135.

[29] A.J. Ghajar, L.M. Tam, Heat transfer measurements and correlations in the transition region for a circular tube with three different inlet configurations, Exp. Therm. Fluid Sci., 8(1) (1994) 79-90.

[30] A.J. Ghajar, L.M. Tam, Flow regime map for a horizontal pipe with uniform wall heat flux and three inlet configurations, Exp. Therm. Fluid Sci., 10(3) (1995) 287-297.

[31] L.M. Tam, A.J. Ghajar, Effect of Inlet Geometry and Heating on the Fully Developed Friction Factor in the Transition Region of a Horizontal Tube, Exp. Therm. Fluid Sci., 15(1) (1997) 52-64.

[32] L.M. Tam, A.J. Ghajar, The unusual behavior of local heat transfer coefficient in a circular tube with a bell-mouth inlet, Exp. Therm. Fluid Sci., 16(3) (1998) 187-194.

[33] A.J. Ghajar, C.C. Tang, W.L. Cook, Experimental investigation of friction factor in the transition region for water flow in minitubes and microtubes, Heat Transfer Eng, 31(8) (2010) 646-657.

[34] H.K. Tam, L.M. Tam, A.J. Ghajar, S.C. Tam, T. Zhang, Experimental investigation of heat transfer, friction factor, and optimal fin geometries for the internally microfin tubes in the transition and turbulent regions, J. Enhanced Heat Transf., 19(5) (2012) 457-476.

[35] H.K. Tam, L.M. Tam, A.J. Ghajar, Effect of inlet geometries and heating on the entrance and fully-developed friction factors in the laminar and transition regions of a horizontal tube, Exp. Therm. Fluid Sci., 44 (2013) 680-696.

[36] L.M. Tam, H.K. Tam, A.J. Ghajar, W.S. Ng, C.K. Wu, The effect of inner surface roughness and heating on friction factor in horizontal mini-tubes, in: 15th International Heat Transfer Conference, Kyoto, Japan, 2014.

[37] J.A. Olivier, J.P. Meyer, Single-phase heat transfer and pressure drop of the cooling of water inside smooth tubes for transitional flow with different inlet geometries (RP-1280), HVAC R Res, 16(4) (2010) 471-496.

[38] J.P. Meyer, J.A. Olivier, Transitional flow inside enhanced tubes for fully developed and developing flow with different types of inlet disturbances: Part II-heat transfer, Int. J. Heat Mass Transf., 54(7-8) (2011) 1598-1607.

[39] J.P. Meyer, J.A. Olivier, Transitional flow inside enhanced tubes for fully developed and developing flow with different types of inlet disturbances: Part I - Adiabatic pressure drops, Int. J. Heat Mass Transf., 54(7-8) (2011) 1587-1597.

[40] J.P. Meyer, J.A. Olivier, Heat transfer and pressure drop characteristics of smooth horizontal tubes in the transitional flow regime, Heat Transfer Eng, 35(14-15) (2014) 12461253.

[41] J.P. Meyer, T.J. McKrell, K. Grote, The influence of multi-walled carbon nanotubes on single-phase heat transfer and pressure drop characteristics in the transitional flow regime of smooth tubes, Int. J. Heat Mass Transf., 58(1-2) (2013) 597-609.

[42] J. Dirker, J.P. Meyer, D.V. Garach, Inlet flow effects in micro-channels in the laminar and transitional regimes on single-phase heat transfer coefficients and friction factors, Int. J. Heat Mass Transf., 77(0) (2014) 612-626.

[43] D.D. Ndenguma, J. Dirker, J.P. Meyer, Transitional flow regime heat transfer and pressure drop in an annulus with non-uniform wall temperatures, Int. J. Heat Mass Transf., 108 (2017) 2239-2252. 
[44] J.P. Meyer, S.M. Abolarin, Heat transfer and pressure drop in the transitional flow regime for a smooth circular tube with twisted tape inserts and a square-edge inlet, Int. J. Heat Mass Transf., 117 (2018) 11-29.

[45] M. Everts, J.P. Meyer, Heat transfer of developing and fully developed flow in smooth horizontal tubes in the transitional flow regime, Int. J. Heat Mass Transf., (2017), Manuscript nr: HMT_2017_2232, submitted on 7 June 2017.

[46] M. Everts, J.P. Meyer, Relationship between pressure drop and heat transfer of developing and fully developed flow in smooth horizontal circular tubes in the laminar, transitional, quasi-turbulent and turbulent flow regimes, Int. J. Heat Mass Transf., (2017), Manuscript nr: HMT_2017_2233, submitted on 7 June 2017.

[47] M. Everts, J.P. Meyer, Flow regime maps for smooth horizontal tubes at a constant heat flux, Int. J. Heat Mass Transf., (2017), Manuscript nr: HMT_2017_2234, submitted on 7 June 2017.

[48] L.M. Tam, A.J. Ghajar, H.K. Tam, S.C. Tam, Development of a flow regime map for a horizontal pipe with the multi-classification Support Vector Machines, in: 2008 Proceedings of the ASME Summer Heat Transfer Conference, HT 2008, 2009, pp. 537-547.

[49] H.K. Tam, L.M. Tam, A.J. Ghajar, C.W. Cheong, Development of a unified flow regime map for a horizontal pipe with the support vector machines, in: AIP Conference Proceedings, 2010, pp. 608-613.

[50] M. Everts, Heat transfer and pressure drop of developing flow in smooth tubes in the transitional flow regime, Masters dissertation, University of Pretoria, Pretoria, 2014.

[51] A. Bakker, R.D. LaRoche, E.M. Marshall, Laminar flow in static mixers with helical elements, in: The Online CFM Book, 2000.

[52] F.T. Ulaby, E. Michielssen, U. Ravaioli, Fundamentals of Applied Electromagnetics, 6th ed., Pearson, Boston, 2010.

[53] C.O. Popiel, J. Wojtkowiak, Simple formulas for thermophysical properties of liquid water for heat transfer calculations [from $\mathrm{O}^{\circ} \mathrm{C}$ to $150^{\circ} \mathrm{C}$ ], Heat Transfer Eng, 19(3) (1998) 87-101.

[54] A.J. Ghajar, J. Kim, Calculation of local inside-wall convective heat-transfer parameters from measurements of local outside-wall temperatures along an electrically heated circular tube, in: M. Kutz (Ed.) Heat-Transfer Calculations, McGraw-Hill, New York, 2006, pp. 23.23-23.27.

[55] S.M. Morcos, A.E. Bergles, Experimental investigation of combined forced and free laminar convection in horizontal tubes, Journal of Heat Transfer, 97(2) (1975) 212-219.

[56] P.F. Dunn, Measurement and Data Analysis for Engineering and Science, 2nd ed., CRC Press, United States of America, 2010.

[57] M. Everts, Single-phase mixed convection of developing and fully developed flow in smooth horizontal circular tubes in the laminar, transitional, quasi-turbulent and turbulent flow regimes, $\mathrm{PhD}$ thesis, University of Pretoria, Pretoria, 2017 (under examination).

[58] J.P. Meyer, Heat transfer in tubes in the transitional flow regime, in: 15th International Heat Transfer Conference, Kyoto, Japan, 2014.

[59] A.K. Kupper, Combined free and forced convection in a horizontal tube under uniform heat flux, Masters dissertation, The University of British Columbia, Vancouver, 1968.

[60] J. Chen, Heat transfer in high laminar, transition and lower turbulent flow regimes for square-edged contraction entrance in a circular tube, $\mathrm{PhD}$ thesis, Oklahoma State University, Oklahoma, 1988.

[61] D.T. Strickland, Heat transfer measurements in the transition region for a horizontal circular tube with a square-edged entrance, Masters dissertation, Oklahoma State University, Stillwater, 1990. 
[62] J.P. Meyer, C.C. Tang, Convective Heat Transfer of Nanofluids in Tubes, in: S.M. Sohel Murshed, C.A. Nieto de Castro (Eds.) Nanofluids: Synthesis, Properties and Applications, Nova Science Publishers, New York, 2014, pp. 155-192.

[63] Y.A. Cengel, Heat and Mass Transfer: A Practical Approach, 3rd ed., McGraw-Hill, Singapore, 2006.

[64] S.W. Churchill, R. Usagi, A general expression for the correlation of rates of transfer and other phenomena, AIChE Journal, 18(6) (1972) 1121-1128.

[65] L.M. Tam, An experimental investigation of heat transfer and pressure drop in the transition region for a horizontal tube with different inlets and uniform heat flux, $\mathrm{PhD}$ thesis, Oklahoma State University, Stillwater, 1995.

[66] S.M. Morcos, Combined forced and free laminar convection in horizontal tubes, $\mathrm{PhD}$ thesis, Iowa State University, Ames, 1974.

[67] D.K. Edwards, V.E. Denny, A.F. Mills, Transfer Processes, 2nd ed., Hemisphere, Washington, DC, 1979.

[68] E.N. Sieder, G.E. Tate, Heat transfer and pressure drop of liquids in tubes, Industrial Engineering Chemistry, 28 (1936) 1429-1435. 